\title{
Antimicrobial resistance and virulence characteristics of Vibrio vulnificus, Vibrio parahaemolyticus and Vibrio harveyi from natural disease outbreaks of marine/estuarine fishes
}

\author{
Mariya Sony $^{\text {a }}$, T.G. Sumithra ${ }^{\text {b, }}$, V.N. Anusree ${ }^{\mathrm{b}}$, P.V. Amala ${ }^{\mathrm{b}}$, K.J. Reshma ${ }^{\mathrm{b}}$, Swapna Alex ${ }^{\mathrm{a}}$, N. \\ K. Sanil ${ }^{\mathrm{b}}$ \\ ${ }^{a}$ Department of Plant Biotechnology, College of Agriculture, Vellayani, Kerala Agricultural University, India \\ ${ }^{\mathrm{b}}$ Marine Biotechnology Division, ICAR-Central Marine Fisheries Research Institute, Post Box No. 1603, Ernakulam North P.O., Kochi 682 018, India
}

\section{A R T I C L E I N F O}

\section{Keywords:}

Aquaculture

Marine

Vibrios

tet gene

Cross-resistance

\begin{abstract}
A B S T R A C T
Vibrio vulnificus, Vibrio parahaemolyticus and Vibrio harveyi are the causative agents of the most severe diseases of marine and brackish aquaculture systems. These are also associated with serious ailments in humans. The present paper unravels the virulence features/genes and antimicrobial resistance (AMR) phenotypes/genes of these Vibrio spp. isolated from natural disease outbreaks of marine/estuarine fishes of India for the first time. Results on virulence features showed that $V$. vulnificus infected fish can pose public health risk. While, it has been found clinically that $V$. parahaemolyticus without $t d h$ and trh genes are pathogenic to fish, even though they are reported to be, not associated with human diseases. It was significant to note that virulence features of $V$. harveyi were induced at increased salinity. Analysis based on the percentage prevalence of susceptible isolates and variation coefficient of zone diameters categorized 17 antibiotics in terms of their efficiency against each fish pathogenic species. Multiple antibiotic resistance index (MARi) of the isolates ranged between 0.058 and 0.47 . Results on MARi and percentage of multidrug resistance strains indicated that $>50 \%$ of the isolates were from low antibiotic usage area. The study generated tetH sequence from $V$. parahaemolyticus for the first time, and the sequence revealed high identity to that of clinical strains. Presence of tetB/ tet $H$ gene was identified as the predictor for the resistance against the first generation tetracycline, the most commonly used antibiotic against Vibrio spp. in aquaculture practices. The data on associations between AMR features predicted certain cross-resistance between antimicrobials within Vibrio spp. Altogether, the paper serves as the baseline for epizootic tracking of public health significant vibrios from diseased fishes, to devise practical guidelines for antibiotic use and to formulate efficient control measures against three Vibrio spp. in aquaculture, targeting final applications in the implementation of national green and healthy aquaculture practices.
\end{abstract}

\section{Introduction}

Global downswing of ocean fishery stocks has paved the way for rapid flourishing in aquaculture practices of different fish and shellfish species (Naylor et al., 2000). Aquaculture is currently recognised as the fastest growing food producing sector globally, and sustainable development of aquaculture practices is very crucial to assure food ssecurity and strengthen the global economy (Olsen and Hasan, 2012). On the other hand, excessive industrialized practices and over-intensive exploitation for boosting the production, has led to the emergence of serious bacterial disease outbreaks in aquaculture (Deng et al., 2020).
Vibriosis is the most prevalent one among different bacterial diseases, and affects a wide range of marine and estuarine fish species (Chatterjee and Haldar, 2012). Among the various Vibrio spp., V. vulnificus, $V$. parahaemolyticus and $V$. harveyi represent the most frequent fish pathogens causing substantial economic losses to marine or estuarine aquaculture practices (Ruwandeepika et al., 2010; Deng et al., 2020). Apart from aquaculture perspectives, these bacteria have emerged as a causative agent of many foodborne, waterborne and zoonotic diseases in humans (Sapkota et al., 2008).

Pathogenicity of vibrios is facilitated by a broad range of virulence factors and genes, which allow them to infect and damage diverse host

\footnotetext{
* Corresponding author.

E-mail address: sumithra.G@icar.gov.in (T.G. Sumithra).
} 
species and finally exit from the infected host (Schroeder et al., 2017). Analysis of major virulence factors/ genes can provide many meaningful insights on pathogenesis and zoonotic potentials of vibrios; which can facilitate the establishment of efficient and enhanced prophylactic measures (Deng et al., 2020). Analysis of antimicrobial resistance (AMR) of pathogens within a specific area is another crucial arena to be investigated for the formulation of effective disease control programs and local antibiotic reduction policies (Deng et al., 2020). Conversely, in developing countries where most of aquaculture is practised, antimicrobial agents are inexpensive, widely available for broad application and regulatory limits for antimicrobial agents are not well defined or closely monitored (Miller and Harbottle, 2018). Higher incidences of diseases in aquaculture practices of these countries has therefore, led to the greater reliance on antibiotics and other antimicrobial supplements, has alleviated the emergence of AMR vibrios (Watts et al., 2017). It has been now recommended that assessment of AMR and identification of association between different AMR characteristics, can prevent the further selection of resistance, configuring critical tool in devising efficient control guidelines (Deng et al., 2020). Despite the alarming rise in reports on prevalence of vibrios from sea food samples and, vibriosis outbreaks from both aquaculture practices and from human health sector, little information is available on the virulence and AMR characteristics of vibrios in diseased fishes of India (Parthasarathy et al., 2016; Narayanan et al., 2020). Further, certain ARGs (AMR encoding genes) and virulence genes in vibrios are proven to be horizontally transferred to other human pathogens (Neela et al., 2009). Therefore, characterization of public health significant fish pathogens in both virulence and AMR perspectives is indispensable for an effective epizootic tracking, and are considered as globally relevant topics of research (Watts et al., 2017).

Keeping in view of these facts, the present study was conducted to analyse the virulence features and AMR characteristics of three fish pathogenic Vibrio spp. viz., V. vulnificus, V. parahaemolyticus and $V$. harveyi recovered from natural disease outbreaks of different marine/ estuarine aquaculture fishes. The results on AMR were scrutinized systematically, to classify the recommended antibiotics against non-cholera vibrios based on the activity. Further, associations of AMR phenotypes in between, and with the detected ARGs were analysed to identify the predictor AMR genes, as well as the cross resistance between antimicrobials of fish pathogens. The findings serve as the baseline data for epizootic tracking and to devise efficient control measures against these three Vibrio spp., in marine/estuarine aquaculture systems, targeting its final applications in ecosystem, aquatic animal and public health perspectives. Further, the results will provide essential guidelines for the local antibiotic use in culture practices, enabling the implementation of national green and healthy aquaculture.

\section{Materials and methods}

\subsection{Bacteria}

Bacterial isolates belonging to three different Vibrio spp. namely,

Table 1

Isolation details of bacterial isolates used in the study.

\begin{tabular}{|c|c|c|c|c|c|c|c|c|c|}
\hline No. & Species & Isolate ID & $\begin{array}{l}\text { Year of } \\
\text { isolation }\end{array}$ & Host & $\begin{array}{l}\text { Culture } \\
\text { system for } \\
\text { host }\end{array}$ & $\begin{array}{l}\text { Tissue of } \\
\text { isolation }\end{array}$ & $\begin{array}{l}\text { Hydrographic parameters } \\
\text { of water during the } \\
\text { outbreak }\end{array}$ & Diagnosis made & $\begin{array}{l}\text { Media used for } \\
\text { isolation* }\end{array}$ \\
\hline 1 & V. vulnificus & $\begin{array}{l}\text { CMFRI/ } \\
\text { VV-05 }\end{array}$ & 2017 & $\begin{array}{l}\text { Trachinotus } \\
\text { blochii }\end{array}$ & Tank & Blood & T: $25^{\circ} \mathrm{C}, \mathrm{S}: 5$ ppt, pH: 6.8 & $\begin{array}{l}\text { Mixed infection } \\
\text { (VV, PD \& SP) }\end{array}$ & BHIA \\
\hline 2 & & $\begin{array}{l}\text { CMFRI/ } \\
\text { VV-04 }\end{array}$ & 2018 & Mugil cephalus & Wild & Liver & T: $25^{\circ} \mathrm{C}, \mathrm{S}:<2 \mathrm{ppt}, \mathrm{pH}: 7.0$ & EUS & ZMA \\
\hline 3 & & $\begin{array}{l}\text { CMFRI/ } \\
\text { VV-08 }\end{array}$ & 2018 & Lates calcarifer & Cage & Kidney & T: $28^{\circ} \mathrm{C}, \mathrm{S}: 2 \mathrm{ppt}, \mathrm{pH}: 6.8$ & $\begin{array}{l}\text { Mixed infection } \\
\text { (VV \& PD) }\end{array}$ & ZMA \\
\hline 5 & & $\begin{array}{l}\text { CMFRI/ } \\
\text { VV-10 }\end{array}$ & 2018 & $\begin{array}{l}\text { Oreochromis } \\
\text { niloticus }\end{array}$ & Cage & Blood & $\mathrm{T}: 31^{\circ} \mathrm{C}, \mathrm{S}: 12 \mathrm{ppt}, \mathrm{pH}: 7.1$ & $\begin{array}{l}\text { Mixed infection } \\
\text { (VV\&VP) }\end{array}$ & TCBSA \\
\hline 6 & & $\begin{array}{l}\text { CMFRI/ } \\
\text { VV-06 }\end{array}$ & 2019 & $\begin{array}{l}\text { Ectroplus } \\
\text { surratensis }\end{array}$ & Tank & Blood & T: $31^{\circ} \mathrm{C}, \mathrm{S}: 22 \mathrm{ppt}, \mathrm{pH}: 7.1$ & $\begin{array}{l}\text { Mixed infection } \\
\text { (VV \& SP) }\end{array}$ & TCBSA \\
\hline 7 & V. parahaemolyticus & $\begin{array}{l}\text { CMFRI/ } \\
\text { VP-11 }\end{array}$ & 2017 & L. calcarifer & Cage & Liver & $\mathrm{T}: 28^{\circ} \mathrm{C}, \mathrm{S}:<2 \mathrm{ppt}, \mathrm{pH}: 7.0$ & $\begin{array}{l}\text { Mixed infection } \\
\text { (VP \& SP) }\end{array}$ & ZMA \\
\hline 8 & & $\begin{array}{l}\text { CMFRI/ } \\
\text { VP-10 }\end{array}$ & 2017 & L. calcarifer & Cage & Kidney & $\mathrm{T}: 28^{\circ} \mathrm{C}, \mathrm{S}:<2 \mathrm{ppt}, \mathrm{pH}: 7.0$ & $\begin{array}{l}\text { Mixed infection } \\
\text { (VP, SP and PD) }\end{array}$ & BHIA \\
\hline 11 & & $\begin{array}{l}\text { CMFRI/ } \\
\text { VP-07 }\end{array}$ & 2018 & M. cephalus & Wild & Liver & $\mathrm{T}: 25^{\circ} \mathrm{C}, \mathrm{S}:<2 \mathrm{ppt}, \mathrm{pH}: 7.0$ & EUS & ZMA \\
\hline 12 & & $\begin{array}{l}\text { CMFRI/ } \\
\text { VP-15 }\end{array}$ & 2018 & $\begin{array}{l}\text { Amphitrion } \\
\text { percula }\end{array}$ & Tank & Kidney & T: $28^{\circ} \mathrm{C}, \mathrm{S}: 25 \mathrm{ppt}, \mathrm{pH}: 7.0$ & $\begin{array}{l}\text { Mixed infection } \\
\text { (VP and VH) }\end{array}$ & TCBSA \\
\hline 13 & V. harveyi & $\begin{array}{l}\text { CMFRI/ } \\
\text { VHa-03 }\end{array}$ & 2017 & T. blochii & Tank & Skin Lesion & $\mathrm{T}: 30^{\circ} \mathrm{C}, \mathrm{S}: 18 \mathrm{ppt}, \mathrm{pH}: 7.4$ & Infection by VH & TCBSA \\
\hline 14 & & $\begin{array}{l}\text { CMFRI/ } \\
\text { VHa-06 }\end{array}$ & 2017 & L. calcarifer & Cage & Liver & $\mathrm{T}: 32^{\circ} \mathrm{C}, \mathrm{S}: 20 \mathrm{ppt}, \mathrm{pH}: 7.4$ & $\begin{array}{l}\text { Mixed infection } \\
\text { (VH, VV \& PD) }\end{array}$ & TCBSA \\
\hline 15 & & $\begin{array}{l}\text { CMFRI/ } \\
\text { VHa-07 }\end{array}$ & 2017 & $\begin{array}{l}\text { Amphitrion } \\
\text { percula }\end{array}$ & Tank & Spleen & T: $28^{\circ} \mathrm{C}, \mathrm{S}: 25 \mathrm{ppt}, \mathrm{pH}: 7.0$ & $\begin{array}{l}\text { Mixed infection } \\
\text { (VH \& PP) }\end{array}$ & BHIA \\
\hline 16 & & $\begin{array}{l}\text { CMFRI/ } \\
\text { VHa-08 }\end{array}$ & 2019 & $\begin{array}{l}\text { Abudefduf } \\
\text { vaigiensis }\end{array}$ & Tank & Blood & T: $26^{\circ} \mathrm{C}, \mathrm{S}: 35$ ppt, pH: 7.1 & Infection by VH & ZMA \\
\hline 17 & & $\begin{array}{l}\text { CMFRI/ } \\
\text { VHa-09 }\end{array}$ & 2019 & A. vaigiensis & Tank & Kidney & T: $26^{\circ} \mathrm{C}, \mathrm{S}: 35$ ppt, pH: 7.1 & Infection by VH & ZMA \\
\hline 18 & & $\begin{array}{l}\text { CMFRI/ } \\
\text { VHa-10 }\end{array}$ & 2017 & $\begin{array}{l}\text { Amphitrion } \\
\text { percula }\end{array}$ & Tank & Blood & T: $28^{\circ} \mathrm{C}, \mathrm{S}: 25 \mathrm{ppt}, \mathrm{pH}: 7.0$ & $\begin{array}{l}\text { Mixed infection } \\
\text { (VH \& VC) }\end{array}$ & BHIA \\
\hline
\end{tabular}

Abbreviations: VP: V. parahemolyticus; VV: V. vulnificus; TCBSA: Thiosulfate-citrate-bile salts-sucrose agar; EUS: Epizootic ulcerative syndrome; ZMA: Zobell Marine Agar; PD: Photobacterium damselae; SP: Shewanella putrefaciens BHIA: Brain Heart Infusion Agar; SA: Streptococcus agalactiae: AV: Aeromonas veronii; VM: Vibrio mimicus; VH: V. harveyi; PP: Psuedoalteromonas piscicida: VC: V. corallyticus; T: Temperature; S: Salinity; ppt: parts per thousand.

Inoculated media were incubated at $30^{\circ} \mathrm{C}$ for $24 \mathrm{~h}$ for isolation. 
$V$. parahaemolyticus, V. harveyi and V. vulnificus, which were systematically collected from various organs of live diseased fishes that have been submitted to Fish Health Section, Marine Biotechnology Division, ICARCMFRI (Indian Council of Agriculture Research-Central Marine Fisheries Research Institute), Kochi, Kerala, India for disease diagnosis during 2017-2019, were used in the present study. Isolation details of these bacteria were included in Table 1. Identification of these isolates was done on the basis of a battery of conventional microbiological tests (Noguerola and Blanch, 2008; Bergey et al., 2012) and 16SrRNA gene sequencing (Weisburg et al., 1991). Further, confirmation of the identification was done using species specific PCR (Table S1). All the isolates were preserved in Zobell Marine Broth (HiMedia) containing 20\% glycerol at ${ }^{-} 80^{\circ} \mathrm{C}$.

\subsection{Molecular characterization by $16 S r R N A$ gene sequencing}

16SrRNA gene sequences of the isolates were submitted to NCBIGenBank database with specific accession numbers (Fig. 1a). The overlapping $820 \mathrm{bp}$ sized sequence of each strain obtained from sequencing reactions using forward and backward primers, was then aligned using CLUSTAL-W (MEGA version 10 software) and the aligned data set was used for phylogenetic analysis by neighbor joining method (MEGA version 10) using Kimura 2-parameter model (Kumar et al., 2016). The corresponding sequence of Streptococcus agalactiae was used as out-group for rooting the tree. Confidence in the tree was estimated by 1000 bootstrap replicates.

\subsection{Analysis of virulent features among the isolates}

Phenotypic features associated with virulence of V. parahaemolyticus, $V$. harveyi and $V$. vulnificus namely, protease, siderophore, haemolysis and urease was checked in all isolates. Proteolytic activity was detected by spotting bacteria on nutrient agar containing $2 \%$ final concentration of skim milk. After incubation at $28{ }^{\circ} \mathrm{C}$ for $24-48 \mathrm{~h}$, formation of a clear halo around the culture spot was checked (Moreno and Landgraf, 1998). Urease and hemolysis were detected by inoculating in Christensen's urea agar and, nutrient agar enriched with $5 \%$ fish blood respectively. Bacterial strains were checked for siderophore producing ability by universal CAS assay as per the recommended protocol (Arora and Verma, 2017). For the isolates which were negative for any of these four virulence features, induction of these activity at higher salinity was checked by conducting similar assays in respective media supplemented with a final concentration of $2.5 \%$ sodium chloride.

Further, genetic determinants of virulence reported in these three Vibrio spp. was checked in all the isolates through gene targeted PCR approach. The screened virulence genes included three genes of $V$. parahaemolyticus namely, $t d h$ (encoding thermostable direct hemolysin, TDH), trh (encoding TDH-related hemolysin, TRH) (Honda and Iida, 1993; Mala et al., 2016) and toxR (involved in regulation of many virulent genes) (Lin et al., 1993), two virulent genes of $V$. harveyi viz., chiA (encoding chitinase) and vhpA (encoding metalloprotease) (Ruwandeepika et al., 2010), as well as one gene of V. vulnificus (variable region within pilF gene associated with potential human pathogenicity) (Roig et al., 2010). For this, genomic DNA was extracted from each isolate by CTAB method (Wilson, 1987) and PCR was done as per the recommended protocol for each sets of primers (Table S1). PCR conditions included initial denaturation $\left(95^{\circ} \mathrm{C}\right.$ for $5 \mathrm{~min}$ ), followed by 35 cycles of denaturation $\left(95{ }^{\circ} \mathrm{C}\right.$ for $1 \mathrm{~min}$ ), annealing (Table S1) and extension $\left(72{ }^{\circ} \mathrm{C}\right.$ for $\left.1.30 \mathrm{~min}\right)$, and final extension at $72{ }^{\circ} \mathrm{C}$ for $10 \mathrm{~min}$. The specific amplifications were verified on $1.5 \%$ agarose gel and through sequencing of the representative amplicon. Furthermore, $v v h A$ PCR product obtained during molecular confirmation of $V$. vulnificus strains using species specific primers (Kaysner and DePaola, 2004) was sequenced (Agrigenome, India) to identify the genetic group associated with diseased fish. For this, the overlapping 455 bp fragment from sequencing reactions using forward and reverse primers, was aligned against other $V$. vulnificus strains using CLUSTAL-W. vvhA sequence of V. vulnificus L-180 strain originally isolated from human blood and, CDC B3547 strain originally isolated from human leg ulcer was included in the analysis for representing genetic group I and group II, respectively (Senoh et al., 2005). Aligned data set was used to perform the phylogenetic analysis by neighbor-joining method (MEGA version 10 software) using Kimura 2-parameter model (Kumar et al., 2016). Confidence in the tree was estimated by 1000 bootstrap replicates.

\subsection{Antibiotic susceptibility test (ABST)}

Susceptibility of the isolates to 17 antibiotics of 7 different classes (Table S2) was analysed using disc diffusion method (Bauer et al., 1966) as recommended by Clinical and Laboratory Standard Institute (CLSI) guideline VET03-A for susceptibility testing of non-fastidious organisms (CLSI, 2006; Baron et al., 2020). Escherichia coli ATCC 25922 strain was run in parallel as a reference quality control strain for ABST. Panel of antibiotics were selected according to the guidelines of National
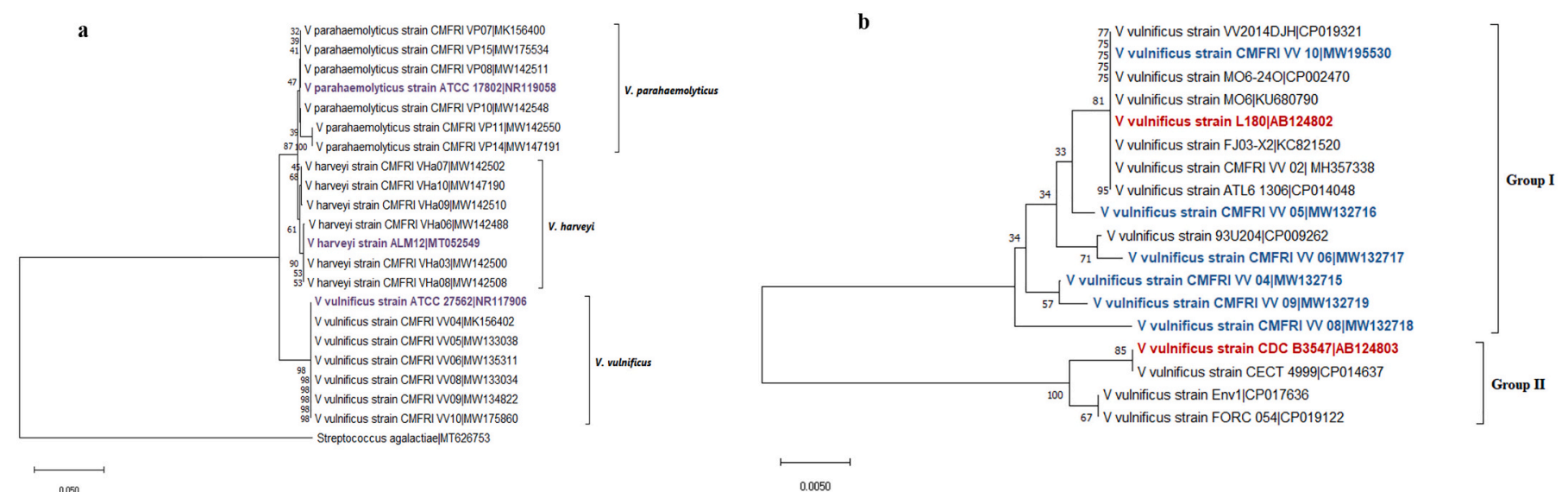

Fig. 1. Comparative phylogenetic analysis of bacterial isolates in the present study. a: Comparative phylogenetic analysis based on $16 S$ rRNA gene sequence. Names of each bacteria, strain ID and corresponding GenBank accession numbers are given. Reference sequences of each species are indicated by purple colored bold letters. (For interpretation of the references to colour in this figure legend, the reader is referred to the web version of this article.) b: Comparative phylogenetic analysis of $V$. vulnificus strains using $v v h A$ sequence.

Names of each bacteria, strain ID and corresponding GenBank accession numbers are given. Reference $V$. vulnificus strains of both groups are represented by red colored bold letters. Strains of the present study are represented by blue colored bold letters. (For interpretation of the references to colour in this figure legend, the reader is referred to the web version of this article.) 
Antimicrobial Resistance Monitoring System (NARMS (National Antimicrobial Resistance Monitoring System), 2019) and CLSI (CLSI, 2017) for Vibrio spp. All the antibiotic discs were purchased from HiMedia Pvt. Ltd., Mumbai, India.

\subsection{Detection of antimicrobial resistance (AMR) genes among fish pathogens}

Major AMR genes encoding resistance against 4 major classes of antibiotics, viz., $\beta$-lactams (bla $a_{S H V}$ and bla $a_{\mathrm{TEM}}$ ), quinolones ( $q n r A, q n r B$ and $q n r S$ ), aminoglycosides (aphA3) and tetracycline (tetM, tetS, tetAC, tetBD, tetEHJ and tetGY) were detected by PCR using the primers and protocols described in Table S1. In short, a total of 17 genes were screened in the present study using genomic DNA isolated from each strain. Briefly, the PCR conditions included initial denaturation $\left(95{ }^{\circ} \mathrm{C}\right.$ for $5 \mathrm{~min}$ ) followed by 30 cycles of denaturation $\left(95^{\circ} \mathrm{C}\right.$ for $1 \mathrm{~min}$ ), annealing (Table S1) as well as extension $\left(72{ }^{\circ} \mathrm{C}\right.$ for $\left.1 \mathrm{~min}\right)$ and final extension at $72{ }^{\circ} \mathrm{C}$ for $10 \mathrm{~min}$. The specific amplifications were verified by $1.5 \%$ agarose gel electrophoresis and through sequencing of the amplicon. After sequencing, the obtained sequences were compared using nucleotide BLAST tool of NCBI to find out the closest GenBank relatives. Further, each obtained sequence was screened through comprehensive antibiotic resistance database (CARD) using default settings (Jia et al., 2016) to verify further on AMR gene family and resistance mechanism encoded by the sequence. Sequences corresponding to AR genes obtained were submitted to GenBank database, NCBI.

\subsection{Data analysis}

Descriptive statistics of inhibition zone diameters in each of the three targeted Vibrio spp. against tested antibiotics was calculated to summarize the data set. Inter-strain variability at each species level and genus level against the tested antibiotics was calculated in terms of variation coefficient \% (VC \%) (Lakhssassi et al., 2005). Normality of the dataset was then tested using Shapiro-Wilk test. Kruskal-Wallis H test was used to compare the zone diameters between the three Vibrio spp. and between different years of isolation. World health organization (WHO) established criteria for the interpretation of antibiotic zone diameter for $V$. parahaemolyticus $V$. harveyi and $V$. vulnificus was then applied in the ABST results using WHONET software version 5.6 for judging of the strains either as resistant (R), susceptible (S) or intermediately susceptible (I). Percentage of isolates in each category was calculated for each isolation year, for the genus Vibrio and for each of the targeted three Vibrio spp. Activity scoring of each antibiotic at the species and at the genus level was done considering both $\%$ of susceptible isolates (S\%) and VC\%, in which score 4, 3, 2, 1 and 0 were assigned for S\%: 100; CV\% < 25, S\%: 75-100; CV\%: 25-50, S\% and CV\%: 50-75, S\%: 25-50; CV\%: 75-100 and S\%: $<25 \%$; CV\% $\geq 100$ respectively (Lakhssassi et al., 2005). Activity score obtained for both S\% and CV\% were added to get the final activity score for each antibiotic. Antibiotics were then grouped into four categories namely, very active (8), fairly active ( $\geq 5$ to $<8$ ), poorly active $(\geq 1$ to $<5$ ) and inactive $(0)$ respectively based on the final activity score.

For the purpose of further analyses, isolates having intermediate susceptibility were considered as susceptible (Rosengren et al., 2009a). Multiple antibiotic resistance (MAR) index was calculated for each isolate using the formula; MAR index $=\mathrm{A} / \mathrm{B}$, where ' $\mathrm{A}$ ' represents the number of antibiotics against which the isolate showed resistance and ' $\mathrm{B}$ ' represents the total number of antibiotics against which the isolate was tested (Krumperman, 1983). After testing for normality of the data set on MAR index using Shapiro test, one way analysis of variance (ANOVA) followed by post-hoc Tukey test was applied to compare the MAR index between the three Vibrio spp. Percentage of multidrug resistant (MDR) strains in each species were also calculated, in which isolates resistant to at least one agent in three or more antimicrobial classes (Magiorakos et al., 2012) was categorized as MDR. Subsequently, results on AMR profiles were scored manually for the presence (1) or absence (0) of resistance to create a binary matrix. The data was then analysed for statistical associations between AMR profiles against different antibiotics and host bacterial species using Fisher's exact test. Subsequently, associations between AMR profiles (not having significant association with species) was calculated using Chi-square tests at the genus level and statistically significant associations were shown as Cramer's value to represent the strength of association (Nasaj et al., 2020). Interpretation of Cramer's value was done in which associations were categorized as no $(\geq 0)$, weak ( 0 to $<0.1$ ), low $(\geq 0.1$ to $<0.3$ ), moderate $(\geq 0.3$ to $<0.5)$ and strong $(\geq 0.5)$ (Crewson, 2006). Further, associations of the phenotypic AMR profiles and to the isolation source (tank/cage/wild) and to the detected AMR genes was calculated in the similar manner. All the statistical tests were conducted using either SPSS, version 16.0, for Windows (SPSS, Chicago, IL) or using R software (Version 3.6.0). In all the tests, value of $p<0.05$ was set to represent significant difference.

\section{Results}

\subsection{Characterization of the isolates at species level}

Identification based on a series of conventional microbiological tests and 16SrRNA gene sequencing designated the bacterial isolates into three Vibrio spp., namely, V. parahaemolyticus, $V$. harveyi and $V$. vulnificus. Major findings during identification of the bacterial isolates are briefly outlined in Table S3. All V. parahaemolyticus, V. harveyi and $V$. vulnificus isolates produced $271 \mathrm{bp}, 121 \mathrm{bp}$ and $501 \mathrm{bp}$ sized amplicon with corresponding species specific primers, confirming the species identification. Further, there was no cross species amplification, showing the specificity of the used primers. Comparative phylogenetic tree analysis of the isolates based on 16SrRNA sequence is depicted in Fig. 1a. Overall, isolates of the same species were closely clustered in the phylogenetic tree. Further, isolates belonging to V. parahaemolyticus and $V$. harveyi were branched together within a single clade, indicating limited genetic diversity between these two species. While $V$. vulnificus formed a distinct separate clade, illustrating evolutionary divergence from the other two Vibrio spp.

\subsection{Incidence of virulent features among the isolates}

Major findings on the incidences of virulent features among the tested isolates are represented in Fig. 2a. Of the total isolates screened for phenotypic virulence features, $66.67 \%, 77.78 \%, 16.67 \%$ and $66.67 \%$ were positive for protease, siderophore, urease and haemolysis respectively. It was found that all the isolates belonging to $V$. parahaemolyticus and $V$. vulnificus were positive for protease, siderophore and haemolysis (Fig. 2b). Another interesting observation was that, there was expression of protease activity for $V$. harveyi in presence of increased salinity in the media. Similarly, urease production of all the species was induced in presence of increased salinity (Fig. 3). However, percentage of isolates exhibiting haemolysis and siderophore production were not altered in increased salinity.

Incidences of all the virulent genes tested were confined to the same species, except chiA gene of $V$. harveyi. Representative sequences of the amplified virulent genes were submitted in GenBank, NCBI (Table 2). Although PCR using chiA of $V$. harveyi primer was found to be present in $V$. parahaemolyticus, there was only $86 \%$ similarity between the two sequences within $96 \%$ query cover. Among the virulence genes of $V$. parahaemolyticus tested, toxR gene, which is involved in the regulation of many other virulent genes, was found to be ubiquitous among $V$. parahaemolyticus isolates. However, there was no incidence of the classical virulence genes from human pathogenic V. parahaemolyticus namely $t d h$ and trh. Among the two virulence genes of $V$. harveyi screened, only chiA were present which was ubiquitous in all the 
$\mathbf{a}$

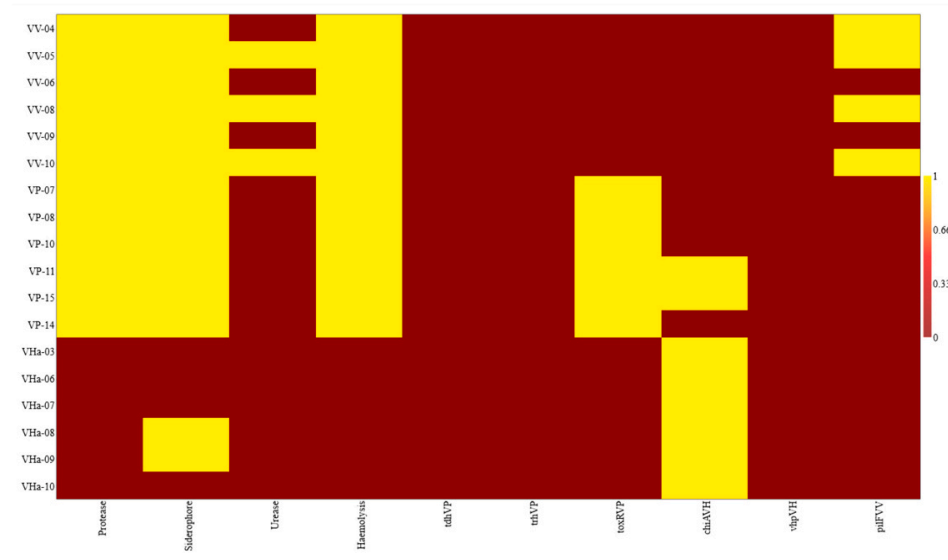

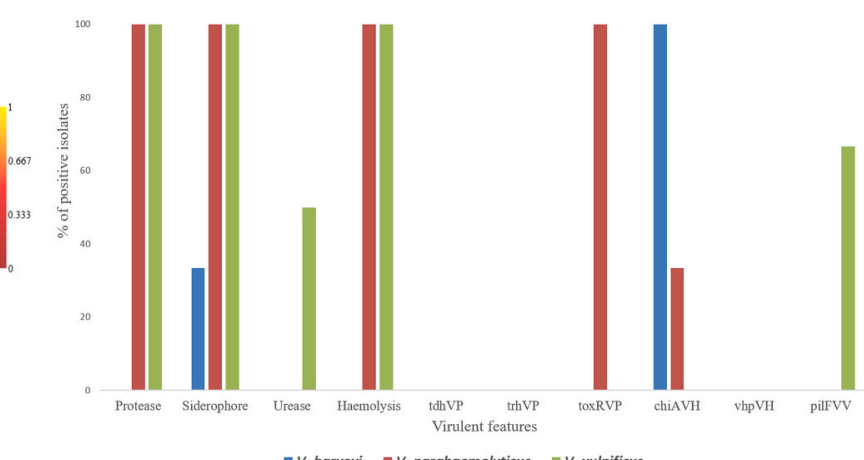

Fig. 2. Incidence of virulent features among the isolates of the present study. a: Strain-wise incidences of virulent features.

b: Species-wise incidences of virulent features.

a

120

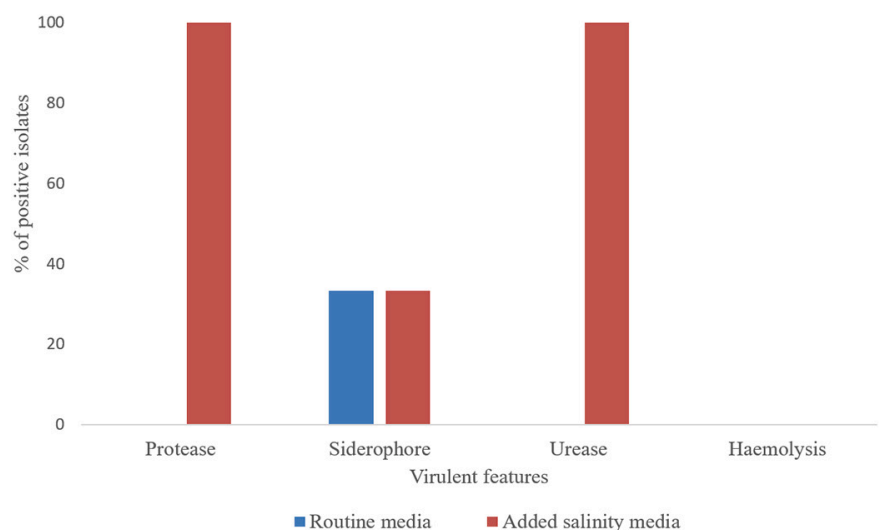

n Routine media $\quad$ Added salinity media

$\mathbf{b}$
120

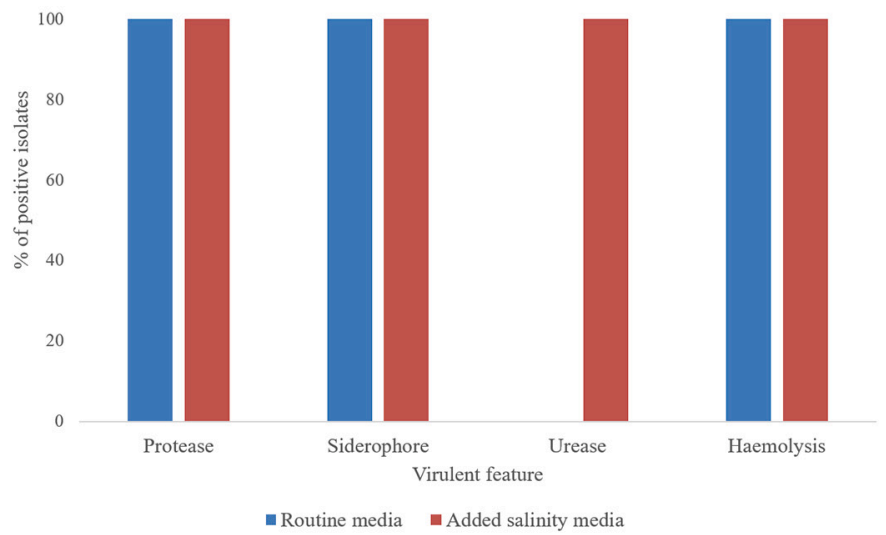

c

120

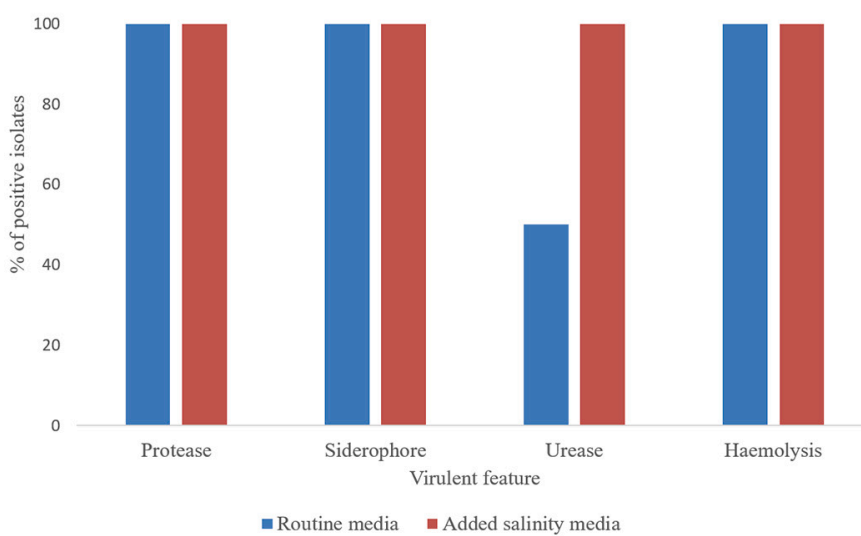

Fig. 3. Incidence of virulent features in presence of increased salinity.

a: Incidence among $V$. harveyi.

b: Incidence among $V$. parahaemolyticus.

c: Incidence of virulent features among $V$. vulnificus.

isolates. More importantly, there was $66.67 \%$ of incidence of classical virulence region (within pilF gene) associated with potential human pathogenicity among V. vulnificus isolates. Comparative phylogenetic tree analysis based on $v v h A$ gene sequence of $V$. vulnificus (Fig. 1b) showed that all the isolates of the present study were clustered along with group I. There were clearly two groups within the species based on 
Table 2

Results of sequence analysis of amplicon obtained through PCR screening of virulent and AMR genes.

\begin{tabular}{|c|c|c|c|c|c|c|c|c|c|c|}
\hline \multirow{2}{*}{$\begin{array}{l}\text { Targeted } \\
\text { AR gene }\end{array}$} & \multirow{2}{*}{$\begin{array}{l}\text { Size of } \\
\text { amplicon } \\
\text { obtained } \\
\text { (bp) }\end{array}$} & \multirow{2}{*}{$\begin{array}{l}\text { GenBank } \\
\text { Accession } \\
\text { Number }\end{array}$} & \multirow{2}{*}{$\begin{array}{l}\text { Host } \\
\text { bacterial } \\
\text { species }\end{array}$} & \multicolumn{3}{|l|}{ NCBI-BLAST results } & \multicolumn{4}{|c|}{ CARD results } \\
\hline & & & & $\begin{array}{l}\text { Closest relative sequence of } \\
\text { the amplicon }\end{array}$ & $\begin{array}{l}\text { NCBI } \\
\text { accession } \\
\text { number }\end{array}$ & ID $\%$ & $\begin{array}{l}\text { Name } \\
\text { of AR } \\
\text { gene }\end{array}$ & AMR gene family & $\begin{array}{l}\text { Closest } \\
\text { species }\end{array}$ & $\begin{array}{l}\text { ID } \\
\%\end{array}$ \\
\hline toxR of VP & $\sim 500$ & MW168989 & VP & $\begin{array}{l}\text { V. parahaemolyticus gene for } \\
\text { ToxR, partial cds }\end{array}$ & AB300869.1 & 100 & & & & \\
\hline chiA of VH & $\sim 250$ & MW168987 & VH & $\begin{array}{l}\text { V. owensii chromosome } 2 \text {, } \\
\text { complete sequence; gene for } \\
\text { chitinase A }\end{array}$ & СР030799.1 & 97.80 & NA & & & \\
\hline chiA of VH & $\sim 250$ & MW244840 & VP & $\begin{array}{l}\text { V. parahaemolyticus } \\
\text { chromosome } 2 \text {, complete } \\
\text { sequence; gene for chitinase } \\
\text { A }\end{array}$ & СР034295.1 & 98.88 & & & & \\
\hline pilF of VV & $\sim 350$ & MW248734 & VV & $\begin{array}{l}\text { V. vulnificus type IV pilus } \\
\text { assembly protein (pilF) gene, } \\
\text { partial cds }\end{array}$ & KF255312.1 & 97.70 & & & & \\
\hline tetEHJ & $\sim 650$ & MW244841 & VP & $\begin{array}{l}\text { Pasteurella multocida } \\
\text { tetracycline efflux MFS } \\
\text { transporter tet }(H) \text { gene }\end{array}$ & СР045724.1 & 100 & tetH & $\begin{array}{l}\text { Major facilitator } \\
\text { superfamily (MFS) } \\
\text { antibiotic efflux } \\
\text { pump }\end{array}$ & P. multocida & 100 \\
\hline \multirow[t]{2}{*}{ tetBD } & $\sim 950$ & MW168990 & VP & $\begin{array}{l}\text { Escherichia coli O157:H7 } \\
\text { tetracycline efflux MFS } \\
\text { transporter } \operatorname{tet}(B) \text { gene }\end{array}$ & СР038419.1 & 100 & tetB & $\begin{array}{l}\text { Major facilitator } \\
\text { superfamily (MFS) } \\
\text { antibiotic efflux } \\
\text { pump }\end{array}$ & $\begin{array}{l}\text { Escherichia } \\
\text { coli }\end{array}$ & 100 \\
\hline & & NS & VH & $\begin{array}{l}\text { V. owensii NUDIX domain- } \\
\text { containing protein }\end{array}$ & СР033144.1 & 95.8 & \multicolumn{2}{|c|}{ No hits found } & & \\
\hline tetS & $\sim 650$ & NS & VP & $\begin{array}{l}\text { V. parahaemolyticus } \\
\text { chromosome } 1 \text { sulfate } \\
\text { permease }\end{array}$ & CP012950.1 & 99.7 & \multicolumn{2}{|c|}{ No hits found } & & \\
\hline tetAC & $\sim 400$ & NS & VH & $\begin{array}{l}V . \text { owensii chromosome } 2 \\
\text { ribulose-phosphate } 3 \text { - } \\
\text { epimerase }\end{array}$ & СР019960.1 & 97.17 & \multicolumn{2}{|c|}{ No hits found } & & \\
\hline$q n r S$ & $\sim 500$ & NS & VV & $\begin{array}{l}V \text {. parahaemolyticus } \\
\text { chromosome II TetR/AcrR } \\
\text { family transcriptional } \\
\text { regulator }\end{array}$ & СР034299.1 & 99.59 & \multicolumn{2}{|c|}{ No hits found } & & \\
\hline
\end{tabular}

Abbreviations: VP: V. parahemolyticus; VV: V. vulnificus; VH: V. harveyi; NA: Not applicable; NS: Not submitted.

$v v h A$ gene sequence, since branching of these groups was exceptionally strong, as indicated by the high bootstrap value of $100 \%$.

\subsection{ABST results}

Summary statistics of zone diameters in each species against the tested antibiotics is shown in Fig. 4. When VC\% indicating inter-strain variation was calculated (Fig. 5a), none of the values were $>100 \%$ indicating none of the antibiotic had very high variable activity against the studied bacteria both at the genus and at species level. Among the tested antibiotics, higher variability $(>25 \%)$ was observed against five antibiotics namely, ampicillin (AMP), amoxicillin-clavulanic acid (AMC), tetracycline (TE), oxytetracycline (OTC) and cotrimoxazole (COT). AMP showed the maximum VC\% at genus level (56.82\%). At species level, AMP (45.67\%), AMC (38.78\%) and OTC (37.75\%) showed maximum $\mathrm{VC} \%$ in their activity against $V$. vulnificus, $V$. harveyi and $V$. parahaemolyticus respectively. Kruskal-Wallis $\mathrm{H}$ test showed that there was a statistically significant difference in inhibition zone diameters against $\beta$ - lactams, one carbapenem and one tetracycline class of antibiotics viz., AMP, AMC, cephalothin (CEP), meropenem (MRP) and OTC between the different species $(p<0.05)$. Thus, a total of 12 antibiotics showed almost similar zone diameter across the targeted three Vibrio spp. $(p>0.05)$.

\subsection{Regrouping ABST results into three profiles}

After interpretation of zone diameters using WHONET software, it was found that $100 \%$ of the isolates in the present study was fully susceptible to 4 antibiotics viz. imipenem (IPM), chloramphenicol (C), doxycycline (DO) and COT irrespective of the species (Fig. 6a). There was no $100 \%$ resistance to any of the recommended antibiotics at the genus level. However, V. parahaemolyticus and V. vulnificus showed $100 \%$ resistance to AMP and cefoxitin (CX) respectively. In case of $V$. harveyi, 100\% resistance was observed against AMP and AMC. Further details of species level ABST profiles are depicted in Fig. 6a-c.

\subsection{Trends in AMR among the studied isolates over the isolation period}

Percentage of the resistant isolates against the recommended antibiotics over the three year investigation period is depicted in Fig. 6d. It was found that there was a steady increase in the percentage of resistant isolates against three antibiotics viz., CX, CIP and streptomycin during 2017-2019. However, Kruskal-Wallis $H$ test showed that there was no significant difference in inhibition zone diameters of the tested antibiotics against vibrios between three different isolation years $(p>0.05)$.

\subsection{Activity scoring of antibiotics against the tested Vibrio spp.}

Based on the final activity score, 4 antibiotics viz., IPM, C, DO and COT were found to be very active against all the targeted three Vibrio spp. There were 7, 6 and 7 very active antibiotics against $V$. harveyi, $V$. parahaemolyticus and $V$. vulnificus respectively (Fig. 5b). Interestingly, none of the recommended antibiotics were graded as inactive against any of the three targeted species. However, three antibiotics viz., AMP, $\mathrm{CX}$ and kanamycin $(\mathrm{K})$ were graded as poorly active antibiotics against all the target species.

\subsection{Antibiotic resistance patterns observed}

There were a total of 11 antibiotic resistant patterns (Table 3) of 

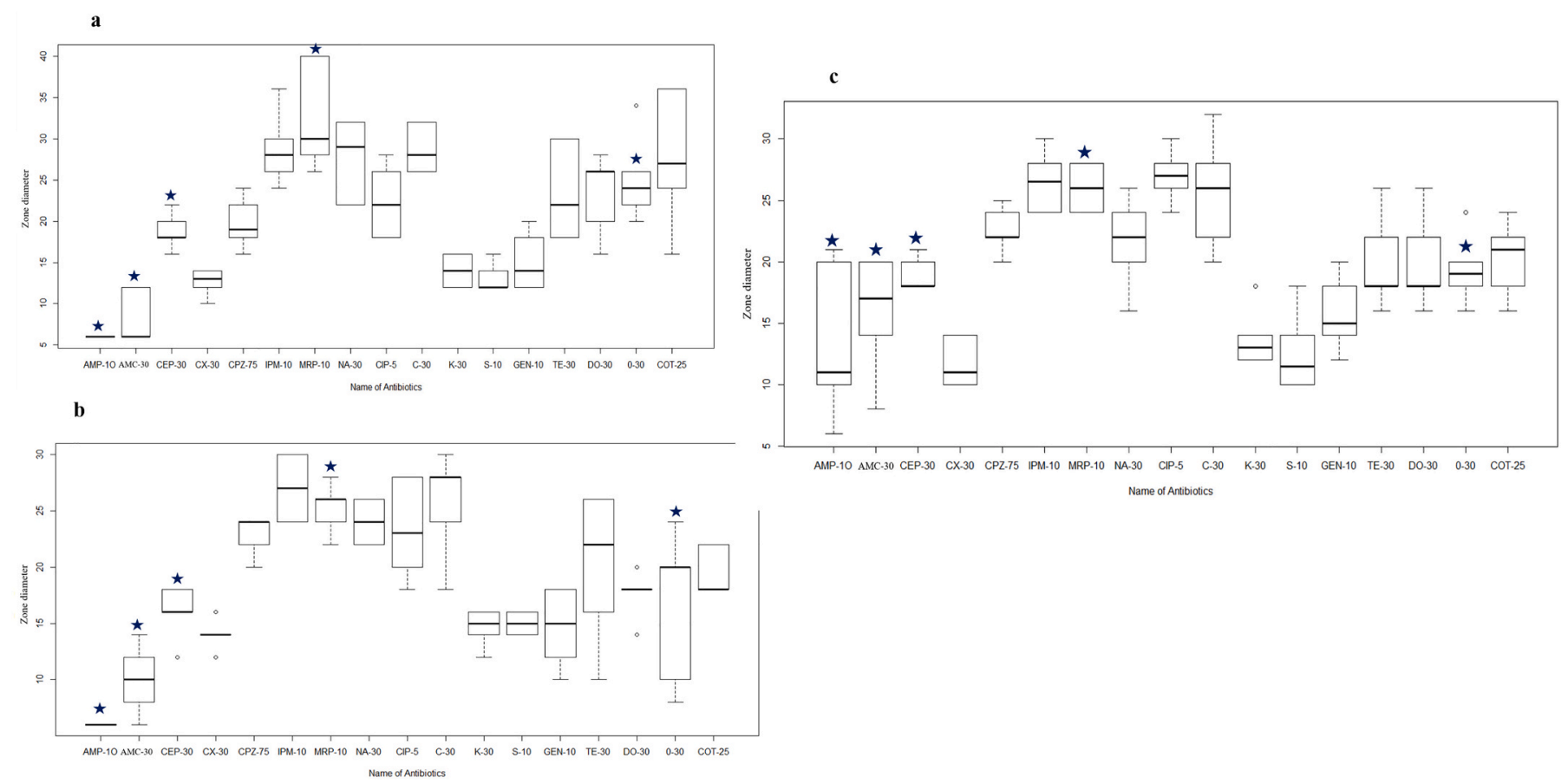

Name of Antbiotics

Fig. 4. Summary statistics of zone diameters in each species against the tested antibiotics.

a: Summary statistics in V. harveyi.

b: Summary statistics in V. parahaemolyticus.

c: Summary statistics in $V$. vulnificus.

* Represent significant difference in inhibition zone diameters between different species $(p<0.05)$.

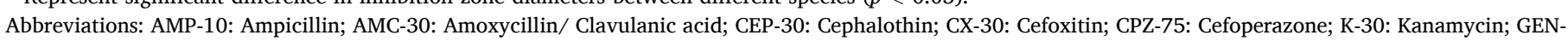

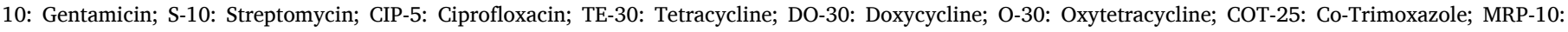
Meropenem; IPM-10: Imipenem; NA30: Nalidixic acid; C30: Chloramphenicol.

which AMP/AMC/CX pattern was the major pattern shown by $38.89 \%$ of the total isolates. The same was the most prevalent pattern shown by $50 \%$ of both VP and VH isolates. In case of $V$. vulnificus, a total of 6 pattern could be observed and each was shown by $16.67 \%$ of the isolates. All the isolates displayed resistance properties to at least one of the recommended antimicrobials tested. When the percentage of multidrug resistant (MDR) strains were calculated, $27.78 \%$ of the isolates in the present study were categorized as MDR and there was no MDR strains within V. vulnificus. Percentage of MDR strains within $V$. harveyi and $V$. parahaemolyticus were $50 \%$ and $33.33 \%$ respectively. MAR index of the isolates varied between 0.058 and 0.47 (Fig. 7a). It was found that $38.89 \%$ of the total isolates had MAR index $>0.2$ (Fig. 7b). The highest MAR index (0.47) was shown by one of $V$. parahaemolyticus strains (CMFRI/VP-15), isolated from an infected fish of ornamental marine hatchery. One way ANOVA showed that there was no significant difference in MAR index between three targeted Vibrio spp. $(p>0.05)$. Similarly, there was no significant association between AMR profiles against the tested antibiotics $(p>0.05)$, and host bacterial species except in case of AMC $(p=0.012)$.

\subsection{Resistant gene profiles among the isolates}

When the isolates were screened for the presence AR genes using reported primers, amplicon having desired size was obtained for 5 genes (Table 1). Results of sequence analysis of the amplicon through NCBIBLAST and comprehensive antibiotic resistance database (CARD) is depicted in Table 2. Accordingly, there were only 2 ARGs viz., tetB and tet $H$ were present in the tested isolates with a prevalence of $5.55 \%$ and $11.11 \%$ respectively. Further, both of these two genes were present only in $V$. parahaemolyticus. The sequences of the genes were submitted GenBank, NCBI under the accession numbers MW168991, MW244841 and MW168990.

\subsection{Association between AMR phenotypes}

When phenotypic resistance to each antibiotic was associated with phenotypic resistance to at least one other drug, we could identify certain significant positive associations (Table S4). The associations could not be estimated for 7 antibiotics as there was no resistant isolates against these antibiotics. There were 5 pairs of antibiotics that were positively associated with at each other AMR $(p<0.05)$ and all associations were found to be strong (Cramer's value $\geq 0.5$ ). Significant strong associations were found between fluoroquinolone resistance phenotype (CIP) to that of one aminoglycoside (K) and OTC. Significantly strong associations were also found between the first generation tetracycline (TE and OTC) resistance phenotypes to that of the first generation cephalosporin (CEP), also in between the first generation tetracyclines.

\subsection{Association of AMR phenotypes to the isolation source and to the detected AR genes}

When the associations between AMR phenotypes and source of isolates were analysed, no significant associations ( $p>0.05$ ) could be pointed out. When association between the presences of tet gene to AMR phenotypes was calculated, a positive significant association was observed between OTC resistance and presence of tetB (Cramer's value as $0.686 ; \mathrm{p}<0.05$ ). Similarly, a positive significant association was observed between the presence of tet $H$ gene to the resistance phenotypes of TE, first and second generation cephalosporin (CEP and CX) and GEN (Cramer's value $\geq 0.5 ; \mathrm{p}<0.05$ ) (Table S4).

\section{Discussion}

Bacterial virulence and antimicrobial resistance (AMR) are the two 

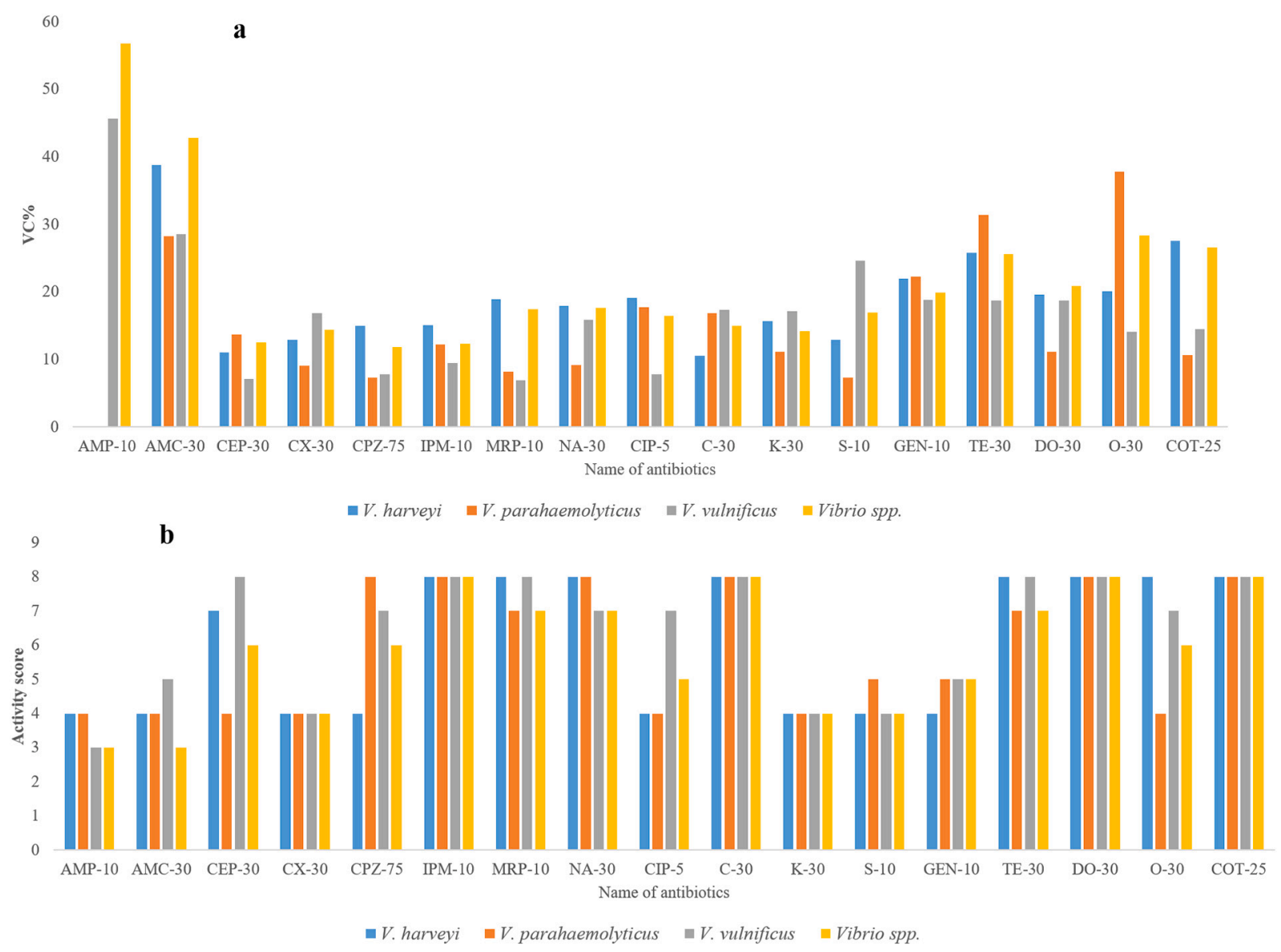

Fig. 5. Results of antibiotic susceptibility test.

a: Inter-strain susceptibility variations in inhibition zone diameters.

b: Activity scoring of antibiotics.

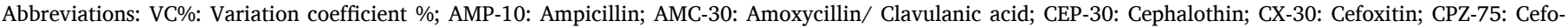

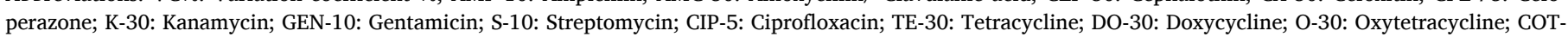
25: Co-Trimoxazole; MRP-10: Meropenem; IPM-10: Imipenem; NA30: Nalidixic acid; C30: Chloramphenicol.

essential features of a pathogen to survive in adverse environmental conditions, and these two aspects have to be characterized together to identify/counteract the threat posed by each pathogen (Beceiro et al., 2013). Consequently, assessment of virulence factors and AMR among aquatic pathogens represents a highlighting research topic in both public health and aquaculture perspectives (Kathleen et al., 2016). Conversely, there is only a limited data on these characteristics of bacteria that were directly sampled from diseased fish of estuarine or marine aquaculture farms of tropical countries (Kathleen et al., 2016). The data will be having more critical public health applications, if such studies are conducted among pathogens having zoonotic significance. $V$. parahaemolyticus, V. harveyi and V. vulnificus are the three Vibrio spp. that pose major concern in human and aquatic animals (Austin, 2010). Further, these pathogens can become a reservoir of AMR genes (Pedersen et al., 2008). Hence, the present paper was conducted to create a data on the virulence factors/genes and AMR phenotypes/genes among these three bacterial species isolated from natural disease outbreaks of marine/estuarine fishes. The generated data was analysed systematically, to classify the recommended antibiotics against these three species, in terms of their activity and to identify the associations between AMR phenotypes/genes to predict the cross resistance.

The genus and species to which a bacterial isolate belongs to, is one of the main factors that interplay between virulence and AMR characteristics (Beceiro et al., 2013). Precise identification thus, form the basic preliminary step in virulence and AMR characterization. Therefore, all the isolates of the present study were confirmed as the target species in the first step. As bacteria in the family Vibrionaceae are very diverse and metabolically versatile, simple methodology based on 16SrRNA sequence is not enough for the precise species identification (Gomez-Gil et al., 2014). Therefore, identification was done based on a panel of conventional microbiological tests (Noguerola and Blanch, 2008; Bergey et al., 2012) and 16SrRNA gene sequencing (Weisburg et al., 1991). Identification was further confirmed by PCR using species specific primers (Kaysner and DePaola, 2004; Di Pinto et al., 2005; Cano-Gómez, 2012). Comparative phylogenetic analysis based on 16SrRNA gene showed that there was a limited genetic diversity between isolates of $V$. parahaemolyticus and $V$. harveyi in consonance to the earlier reports (Sawabe et al., 2013). While V. vulnificus isolates formed a distinct separate clade, illustrating evolutionary divergence from the other two Vibrio spp.

In order to create the data on classical virulence features/genes among the isolates from diseased fish, four virulent features and six genes were targeted in the present study. As Ruwandeepika et al. (2010) reported that vibrios in aquatic environment can acquire virulence features/genes from other vibrios through horizontal gene transfer (HGT), incidences were checked in all the isolates, irrespective of the species. The four virulent features targeted in the study included, protease, haemolysin, urease and siderophore, since expression of these can play significant role in the pathogenicity of vibrios (Zhang and Austin, 2000; Aguirre-Guzman et al., 2004; Ruwandeepika et al., 2010). The targeted genes comprised of, $t d h$ (encoding thermostable direct hemolysin, TDH), trh (encoding TDH-related hemolysin, TRH) (Honda and 

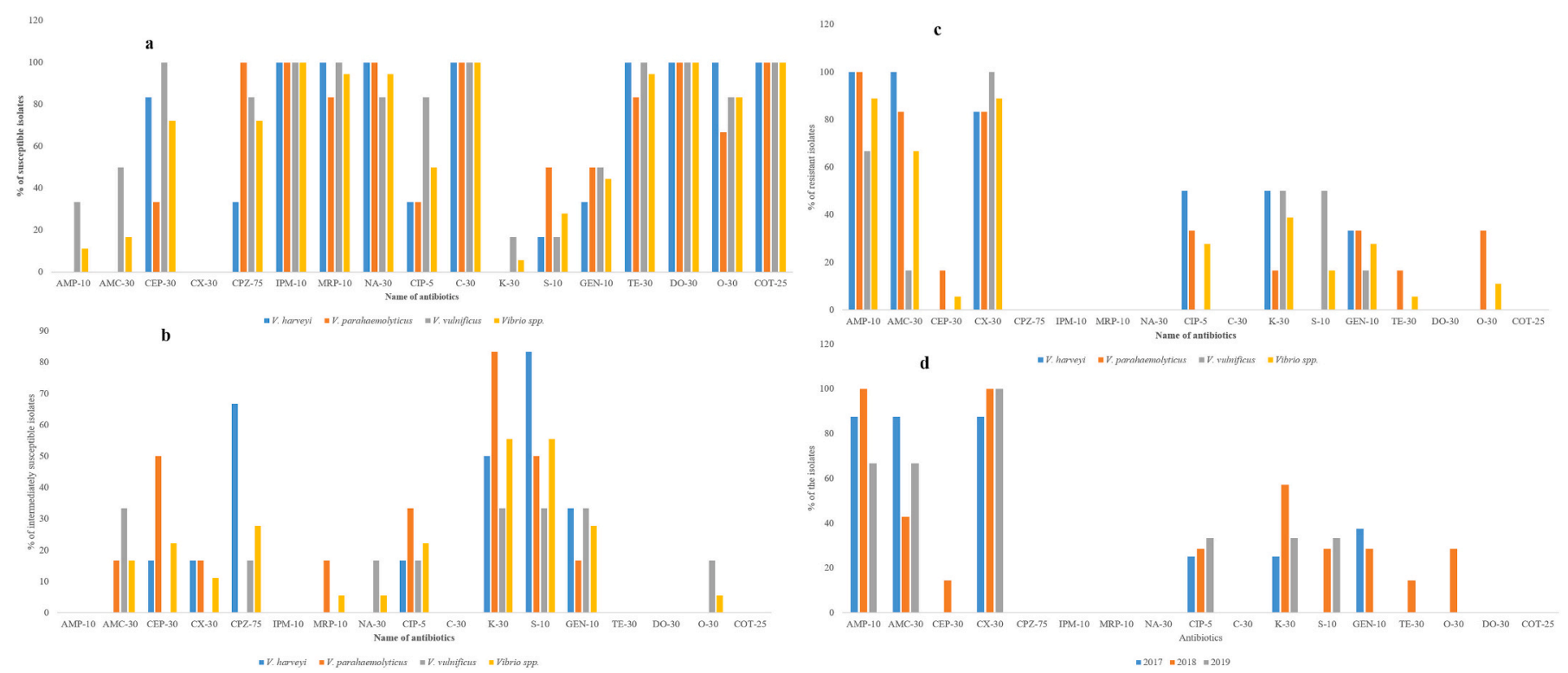

Fig. 6. Percentage of isolates in each category of antibiotic resistance.

a: Percentage of susceptible isolates.

b: Percentage of intermediately susceptible isolates.

c: Percentage of resistant isolates.

$\mathrm{d}$ : Percentage of resistant isolates in each year.

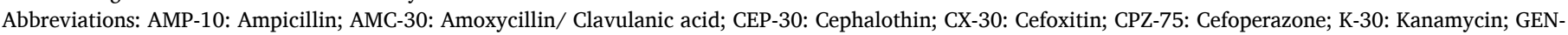

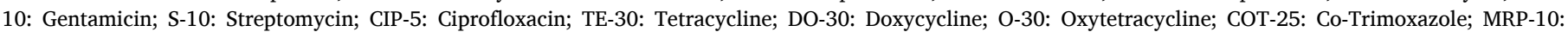
Meropenem; IPM-10: Imipenem; NA30: Nalidixic acid; C30: Chloramphenicol.

Table 3

Antibiotic resistant pattern and multiple antimicrobial resistance (MAR) indices.

\begin{tabular}{|c|c|c|c|c|c|c|}
\hline \multirow{2}{*}{$\begin{array}{l}\text { Sl. } \\
\text { No. }\end{array}$} & \multirow{2}{*}{$\begin{array}{l}\text { Antibiotic resistant } \\
\text { pattern }\end{array}$} & \multirow{2}{*}{$\begin{array}{l}\text { MAR } \\
\text { index }\end{array}$} & \multicolumn{4}{|c|}{$\%$ of isolates } \\
\hline & & & VP & VV & VH & $\begin{array}{l}\text { Vibrio } \\
\text { spp. }\end{array}$ \\
\hline 1 & $\mathrm{CX}$ & 0.058 & 0 & 16.67 & 0 & 5.56 \\
\hline 2 & $\mathrm{CX} / \mathrm{S}$ & 0.117 & 0 & 16.67 & 0 & 5.56 \\
\hline 3 & AMP/AMC/CX & 0.17 & 50 & 16.67 & 50 & 38.89 \\
\hline 4 & $\mathrm{AMP} / \mathrm{CX} / \mathrm{K}$ & 0.17 & 0 & 16.67 & 0 & 5.56 \\
\hline 5 & AMP/AMC/GEN & 0.17 & 16.67 & 0 & 0 & 5.56 \\
\hline 6 & $\mathrm{AMP} / \mathrm{CX} / \mathrm{K} / \mathrm{S}$ & 0.24 & 0 & 16.67 & 0 & 5.56 \\
\hline 7 & $\begin{array}{l}\mathrm{AMP} / \mathrm{CX} / \mathrm{CIP} / \mathrm{GEN} / \\
\mathrm{OTC}\end{array}$ & 0.29 & 16.67 & 0 & 0 & 5.56 \\
\hline 8 & $\mathrm{AMP} / \mathrm{AMC} / \mathrm{CX} / \mathrm{CIP} / \mathrm{K}$ & 0.29 & 0 & 0 & 16.67 & 5.56 \\
\hline 9 & $\mathrm{AMP} / \mathrm{CX} / \mathrm{K} / \mathrm{S} / \mathrm{GEN}$ & 0.29 & 0 & 16.67 & 0 & 5.56 \\
\hline 10 & $\begin{array}{l}\text { AMP/AMC/CX/CIP/ } \\
\text { K/GEN }\end{array}$ & 0.35 & 0 & 0 & 33.33 & 11.11 \\
\hline 11 & $\begin{array}{l}\mathrm{AMP} / \mathrm{AMC} / \mathrm{CEP} / \mathrm{CX} / \\
\mathrm{CIP} / \mathrm{K} / \mathrm{TE} / \mathrm{OTC}\end{array}$ & 0.47 & 16.67 & 0 & 0 & 5.56 \\
\hline
\end{tabular}

Abbreviations: VP: V. parahemolyticus; VV: V. vulnificus; VH: V. harveyi; AMP: Ampicillin; AMC: Amoxycillin/ Clavulanic acid; CX: Cefoxitin; K: Kanamycin; GEN: Gentamicin; S: Streptomycin; CIP: Ciprofloxacin; TE: Tetracycline; OTC: Oxytetracycline.

Iida, 1993; Mala et al., 2016) and toxR (involved in the regulation of many virulent genes) (Lin et al., 1993) of $V$. parahaemolyticus, chiA (encoding chitinase) and $v h p A$ (encoding metalloprotease) (Ruwandeepika et al., 2010) of $V$. harveyi viz., as well as variable region within pilF gene associated with potential human pathogenicity of $V$. vulnificus (Roig et al., 2010). Among the four phenotypic virulence features, $66.67 \%, 77.78 \%, 16.67 \%$ and $66.67 \%$ were positive for protease, siderophore, urease and haemolysis respectively. Despite their role as a serious pathogens of various fishes, the pathogenicity mechanisms of these three Vibrio spp., among aquatic animals have yet to be fully elucidated (Austin and Zhang, 2006). It was found in our study that all the isolates belonging to $V$. parahaemolyticus and $V$. vulnificus were positive for protease, siderophore and haemolysis in both presence and absence of added salinity. Further, prevalence of urease activity was increased to $100 \%$ in the presence of added salinity. The results revealed that all these four virulence features were ubiquitously present in fish pathogenic isolates of $V$. parahaemolyticus and $V$. vulnificus, and may well exert significant roles in fish pathogenicity, similar to the earlier findings in different animal models (Litwin et al., 1996; Chao et al., 2009; Khouadja et al., 2013). Conversely, among virulence features of $V$. harveyi, only siderophore was found to be expressed in the absence of added salinity. Interestingly, the prevalence rate of protease and urease activity was increased from $0 \%$ to $100 \%$ for $V$. harveyi in presence of added salinity of the media. Kautsky et al. (2000) as well as Selven and Philip (2012) noted increased virulence of $V$. harveyi isolates for shrimps (Fenneropenaeus indicus) at increased salinity through in vivo studies, even though they did not study the virulence features of $V$. harveyi at increased salinity, and our findings might be one of the reason for their observation. At the same time, all $V$. harveyi isolates of the present study were negative for haemolysis in both the presence and absence of salinity, suggesting that the ability for haemolysis is not necessary for causing fish pathogenicity. In consonance with our findings, absence of correlation between haemolytic activity and virulence of $V$. harveyi among aquatic animals has been reported earlier (Soto-Rodriguez et al., 2003; Zhang et al., 2020).

Incidence of virulent genes was found to be confined to the same species, excluding the possibility of HGT between the three species. Even though there was amplification of chiA gene of $V$. harveyi from $V$. parahaemolyticus, there was only $86 \%$ similarity between the two sequences within $96 \%$ query cover, showing that the gene was not acquired through HGT. The similar observation was also done by Mohamad et al. (2019) among the isolates from diseased fishes of Malaysia. Certain authors have checked the presence of PCR amplification using the specific primers and used as the criteria for claiming the presence or absence of HGT (Ruwandeepika et al., 2010; Deng et al., 2020). The results of the present study therefore, pointed out the need for the sequence analysis of the genes, before claiming the possibility of 
$\mathbf{a}$

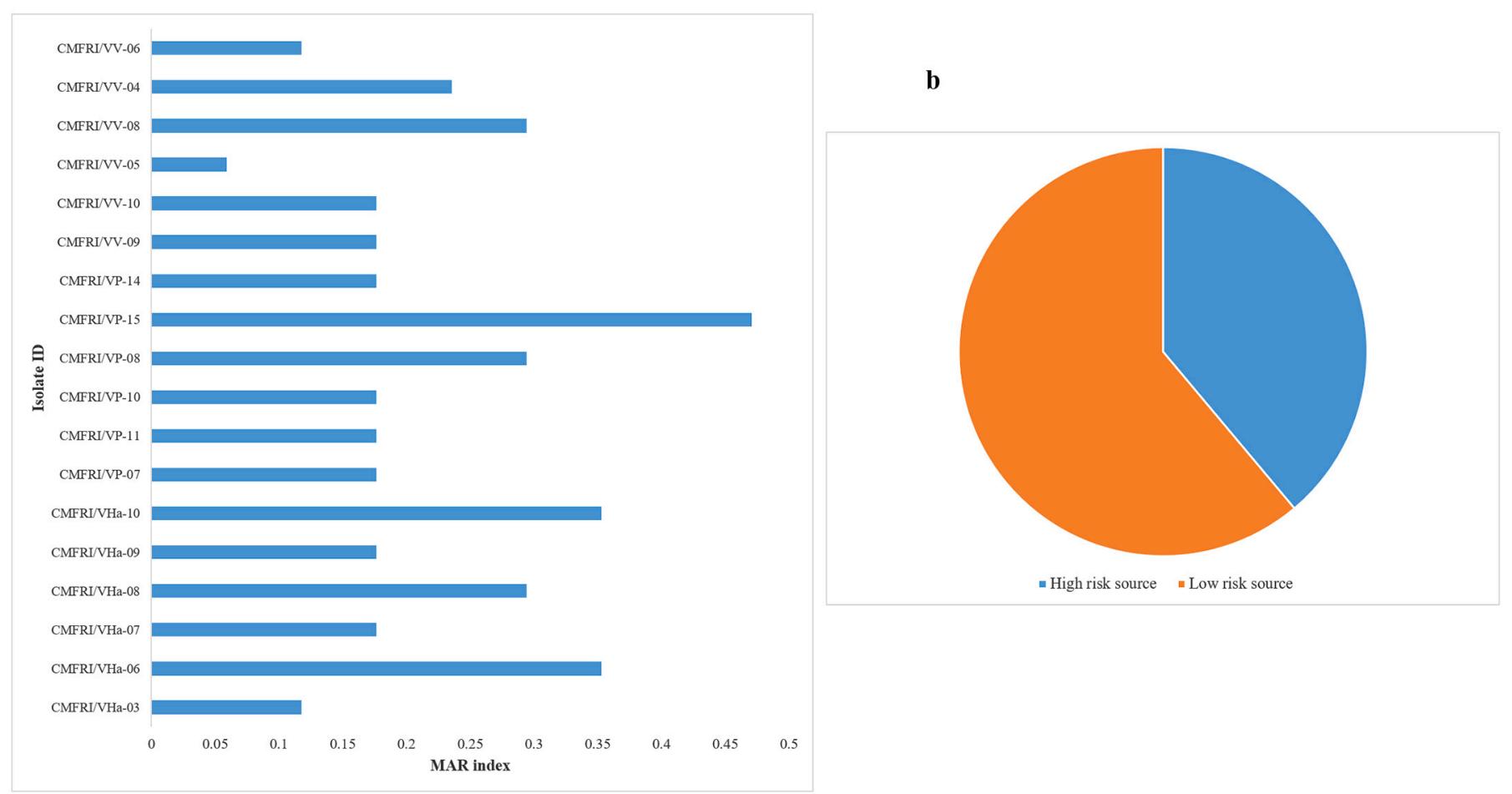

Fig. 7. Multiple antibiotic resistance (MAR) index of the isolates in the present study. a: Strain-wise MAR index.

b: Categorization of the isolates based on MAR index.

Isolates having MAR index $>0.2$ were considered to be recovered from low risk sources of antibiotic contamination (Krumperman, 1983).

horizontal gene transfer (HGT). Among the virulence genes of $V$. parahaemolyticus tested, toxR gene, which is involved in the regulation of several virulent genes (Lin et al., 1993), was found to be ubiquitous in our $V$. parahaemolyticus isolates, similar to the observation of Yang et al. (2017). However, incidence of classical virulence genes of human pathogenic $V$. parahaemolyticus strains namely $t d h$ and trh (Zhao et al., 2011; de Menezes et al., 2020) was nil. In consonance with our findings, Khouadja et al. (2013) and Mohamad et al. (2019) found that all $V$. parahaemolyticus isolates from diseased fish (Dicentrarchus labrax) were negative for $t d h$ and trh genes, and proved that these classical virulent features were not necessary for causing fish pathogenicity. Different authors have identified that expression of protease activity as one of the major virulence factors in tdh and trh negative V. parahaemolyticus isolates (Ottaviani et al., 2005; Khouadja et al., 2013), in consonance with our findings. Of the virulence genes of $V$. harveyi, only chiA was present which was ubiquitous in all the isolates. Deng et al. (2000) and Mohamad et al. (2019) have also noted that the high prevalence rate of chiA among $V$. harveyi isolates of diseased marine fish from South China and Malaysia respectively. Conversely, vhpA, another typical virulence gene of $V$. harveyi was absent in all the isolates of the present study. In consonance with our finding, $v h p A$ was reported to be absent in all the isolates of $V$. harveyi from diseased cultured fish of China, irrespective of their virulence (Xu et al., 2017; Zhu et al., 2017). However, Mohamad et al. (2019) found that $50 \%$ of $V$. harveyi isolates from diseased fish of Malaysia were positive for $v h p A$ gene. During the virulence typing of $V$. vulnificus, all the tested virulence features were found to be widely prevalent. Further, there was $66.67 \%$ of incidence of classical virulence region (within pilF gene) associated with potential human pathogenicity. Comparative phylogenetic tree analysis based on $v v h A$ gene sequence also showed that all the isolates of the present study were clustered along with genetic type I to which human clinical strains are associated (Senoh et al., 2005). In short, all the tested virulence associated data showed that $V$. vulnificus infected fish can pose a major public health risk. The hypothesis is further supported by the case reports of $V$. vulnificus infections in humans after handling infected fish (Chan et al., 1999; Vinh et al., 2006).

Assessment of AMR among aquaculture bacteria is another crucial characteristic that has to be regularly updated for evaluating the public health risk as well as for the sustainable farming practices (Deng et al., 2020). Selection of the panel of antibiotics to be tested is very important in the assessment, and has to be based on the targeted bacterial genera and species. The antibiotics against which the target species/genera are naturally resistant, have to be excluded from the analysis to avoid the misinterpretations (Kathleen et al., 2016). Accordingly, the recommended panel of antibiotics against non-cholera vibrios by CLSI (CLSI (Clinical and Laboratory Standards Institute), 2017) and National Antimicrobial Resistance Monitoring System (NARMS (National Antimicrobial Resistance Monitoring System), 2019) were only selected for the study. Established criteria by WHO (World Health Organization) for the interpretation of antibiotic inhibition zone diameter for $V$. parahaemolyticus $V$. harveyi and $V$. vulnifcus was applied on the obtained zone diameter results, for judging the AMR pattern using WHONET software. It was found that $100 \%$ of the isolates was fully susceptible to 4 antibiotics viz. imipenem (IPM), chloramphenicol (C), doxycycline (DO) and cotrimoxazole (COT) irrespective of the species. In consonance with our findings, high susceptibility of vibrios against these antibiotics has been reported by different authors (Ottaviani et al., 2001; Al-Othrubi et al., 2014; Narayanan et al., 2020). There was no $100 \%$ resistance to any of the recommended antibiotics at the genus level. However, V. parahaemolyticus and V. vulnificus showed $100 \%$ resistance to ampicillin (AMP) and cefoxitin (CX) respectively. In case of V. harveyi, 100\% resistance was observed against AMP and amoxicillinclavulanic acid (AMC). High resistance of bacteria from aquatic environments especially vibrios, towards ampicillin and other $\beta$-lactam 
groups of antibiotics has already been reported by the researchers (Elmahdi et al., 2016; Kathleen et al., 2016; Drais et al., 2018; Mohamad et al., 2019), which was not surprising as these antibiotics were among the first antibiotics introduced since the discovery of penicillin. Similarly, absence of resistance against less commonly used drugs viz., third generation cephalosporin, carbapenem groups, chloramphenicol, doxycycline and co-trimoxazole confirmed that level of resistance among bacteria is related to the frequency of antibiotics usage as hypothesized by other researchers (Austin and Anderson, 1999; Hatha et al., 2005; Lim and Kasing, 2013). The results also suggest that implementation of strict policies on the use of antibiotics by the government can substantially reduce the dissemination of antibiotic resistant bacteria.

Activity scoring of each antibiotics was followed to group the recommended antibiotics into three categories as very active (8), fairly active ( $\geq 5$ to $<8$ ), poorly active $(\geq 1$ to $<5$ ) and inactive $(0)$ respectively with regard to their reaction against the targeted species. In this aspect, the variability rate of susceptibility to 17 antibiotics by means of VC (variation coefficient) of inhibition zone diameters was calculated and included along with the \% of susceptible isolates, for judging each antibiotic against a target species. Higher the VC\% indicates that, the corresponding antibiotic has a variable activity against the studied bacteria, so that, in vivo antibacterial action of that antibiotic against target bacteria will be more unpredictable. Conversely, low VC\% of an active drug signifies that the antibacterial action is stable and regular (Lakhssassi et al., 2005). Certain investigators have used the same to select antibiotics against specific pathogens (Mellado et al., 2001; Lakhssassi et al., 2005). However, there was no previously published literature dealing with the categorization of antibiotics against Vibrio spp. by taking into consideration of both VC\% and \% of susceptible isolates. When VC\% was calculated, higher variability ( $>25 \%$ ) was observed against five antibiotics viz., AMP, AMC, tetracycline (TE), oxytetracycline (OTC) and COT. In short, higher variability was observed against older drugs than with more recent ones, indicating more stable results with recent antibiotics as originally observed by Lakhssassi et al. (2005). At species level, AMP (45.67\%), AMC (38.78\%) and OTC (37.75\%) showed maximum VC\% against $V$. vulnificus, $V$. harveyi and $V$. parahaemolyticus respectively, showing that the activities of these antibiotics are unstable and irregular and, may be incapable of treating the infections caused by the respective species, at certain times. Based on the final activity score calculated, 4 antibiotics viz., IPM, C, DO and COT were found to be very active against all the targeted three Vibrio spp. Interestingly, none of the recommended antibiotics were graded as inactive against any of the three targeted species. However, three more commonly used antibiotics viz., AMP, CX and kanamycin (K) were graded as poorly active antibiotics against all the target species, confirming that level of resistance among bacteria is related to the frequency of antibiotics usage as hypothesized by other researchers (Austin and Anderson, 1999; Hatha et al., 2005; Lim and Kasing, 2013). In this study, AMR patterns of the targeted species were highly variable. There were a total of 11 AMR patterns of which AMP/AMC/CX pattern was the major pattern shown by many of the isolates. Maximum variable pattern was observed among $V$. vulnificus. All isolates displayed resistance properties to at least one of the recommended antimicrobials tested. Multidrug resistant (MDR) phenotype was defined as acquired nonsusceptibility to at least one agent in $\geq 3$ antimicrobial categories (Magiorakos et al., 2012). As per this criteria the percentage of MDR strains in each species were calculated, $27.78 \%$ of the isolates in the present study were categorized as MDR strains. There was no MDR strains within $V$. vulnificus. Multiple antibiotic resistant (MAR) index analysis, is another criteria introduced by Krumperman (1983) to identify the extent of antibiotic contamination in the source of bacterial isolation (Osundiya et al., 2013). It is hypothesized that isolates with MAR $<0.2$ are recovered from low risk sources of antibiotic contamination while isolates with MAR $>0.2$ were from high risk sources (Krumperman, 1983). In this study, the MAR index ranged between
0.058 and 0.47 . It was found that $38.89 \%$ of the total isolates had MAR index $>0.2$, while Mohamad et al. (2019) showed that approximately $75 \%$ of Vibrio isolates from diseased fishes of Malaysia showed MAR index of $>0.20$. One way ANOVA showed that there was no significant difference in MAR index between three Vibrio spp., again confirming that MAR index of the isolate is related to the source of isolation rather the species as indicated by other studies (Osundiya et al., 2013; Gufe et al., 2019). The highest MAR index was shown by CMFRI/VP-15 strain which was isolated from an infected fish of ornamental marine hatchery, showing that the isolate was from a high risk source where antibiotics were frequently used. Even though specific history of the case could not be traced back, heavy use of antibiotics and resultant high MAR index of the bacterial isolates has been reported from ornamental fish farms by different authors (Preena et al., 2020), suggesting the need for strict regulatory interventions in the area. Altogether, results on MAR index and MDR \% revealed that more than 50\% of the isolates were from low antibiotic usage area. Additionally, when the associations between AMR phenotypes and isolation source of isolates were analysed, no significant associations ( $p>0.05$ ) could be pointed out, suggesting that, there is no difference from the isolates of aquaculture practices and wild disease outbreaks, suggesting that AMR in fish pathogens of marine/estuarine systems of India is still in its infancy. When the differences in the AMR occurrence of these fish pathogens over the studied years were examined, it was found that there was a steady increase in the percentage of resistant isolates against three antibiotics viz., CX, CIP and streptomycin. However, there were no significant difference in inhibition activities (zone diameters) of the studied antibiotics between investigated years ( $p>0.05$ ). In brief, there was no conclusive increasing trends in AMR of these pathogens over the study period, which was an expected result, as more than $50 \%$ of the isolates were from low antibiotic usage area (MAR index results), while the rising drug resistance is mainly caused by increased use of antimicrobials (Zhang et al., 2020). The results again reinforce the hypothesis that AMR in fish pathogens of marine/estuarine systems of India is still in its infancy. However, the need for continuous monitoring of AMR patterns should not be overlooked and the community should be educated on the awareness of AMR and its implication on human health and environment.

In order to depict the genetic basis of AMR among the present isolates, a total of 17 genes responsible for resistance to different antibiotics ( $\beta$-lactams, quinolones, kanamycin and tetracycline) were screened as the next step using reported primers. Two AMR genes (ARGs) viz., tetB and $t e t H$ were found to be present in the tested isolates with a prevalence of $5.55 \%$ and $11.11 \%$ respectively. Absence of other genes in the presence of resistance phenotype warrant future research targeting more diverse AR genes among vibrios from marine/estuarine aquaculture environments. However, such discrepancies between AMR phenotypes and prevalence of ARGs has been observed by different authors (Dang et al., 2006; Kitiyodom et al., 2010; Raissy et al., 2012; Safain et al., 2020), which might be due to the presence of other resistance mechanisms which were not investigated in the present study. Another possible explanation is that resistance phenotypes can be expressed upon the stimulation of many different genetic factors (Van et al., 2020). Thus, AMR mechanisms among vibrio isolates from diseased marine/estuarine fish deserve further detailed investigation that might provide critical insights into barriers for the emergence or spread of resistance phenotypes. Antimicrobials belonging to tetracycline group are the most commonly used drugs in human/veterinary/ aquatic animal treatment and the widespread use of tetracycline might be the reason for the occurrence of tet genes among the microbes from fish. In accordance with our findings, higher prevalence of tetB among microbes of fish farms was already reported (Furushita et al., 2003). Both of the detected genes ( $t e t B$ and $t e t H$ ) belong to the major facilitator superfamily (MFS) of transport proteins and encode active efflux pumps which transport tetracycline group of antibiotics out of cells (Roberts, 1996). The present study forms the first report on $t e t H$ gene sequence from vibrios, however, the detected tetH gene showed 100\% homology with corresponding gene 
of other bacterial genera (Histophilus spp., Pasteurella spp., Mannheimia spp., Glaesserella spp., Acinetobacter spp., Psychrobacter spp., Moraxella spp., Aeromonas spp., Haemophilus spp., Actinobacillus spp.). Similarly, tet $B$ gene showed $100 \%$ homology with corresponding genes of same species and other bacterial genera (Salmonella spp., Proteus spp., Providencia spp., Escherichia spp., Acinetobacter spp., Morganella spp., Citrobacter spp., Moraxella spp., Aeromonas spp., Klebsiella spp., Avibacterium spp. and Enterobacter spp.). The results indicated that both tetH and tetB genes moved between different genera via HGT and, warrant additional research to determine how the genes become incorporated into a wide range of bacterial species. High identity of tet gene sequences from fish farm bacteria to those reported for clinical strains has already been reported (Furushita et al., 2003). The location of tetH and tetB genes on transposable elements might be the reason for incorporation into a wide range of bacterial species (Kehrenberg et al., 2001; Babetsa et al., 2012). Finally, presence of tet genes among fish pathogens, suggests that a wide spectrum of tet genes are to be used in future studies to provide a more comprehensive view of tetracycline resistance among vibrio isolates from diseased fish.

There is a great emerging concern that bacterial strains that are resistant to particular antibiotics may easily acquire cross-resistance to other antibiotics (Tsukamoto et al., 2013). As statistical evaluation of the associations between resistance phenotypes can predict co-selection (Rosengren et al., 2009b), results of the present study was analysed to identify the significant associations between AMR phenotypes. Surprisingly, we could point out 5 significant strong associations between different AMR phenotypes of vibrios. Significant strong associations were found between fluoroquinolone resistance phenotype (CIP) to that of one aminoglycoside (K) and OTC. Significant strong associations were also found between the first generation tetracycline (TE and OTC) resistance phenotypes to that of the first generation cephalosporin (CEP), also in between the first generation tetracycline. In consonance with our findings, higher incidence of cross resistance between aminoglycosides and fluoroquinolone, as well as between fluoroquinolone and tetracycline has been observed in different bacterial genera (Tsukamoto et al., 2013; Hwang and Hooper, 2014; Marotta et al., 2019). Cross resistance between completely unrelated drug groups was also reported in different bacteria (Cesur and Demiröz, 2013). However, studies on the association of different AMR phenotypes within vibrios has not been conducted earlier. Even though pointing out the reason for this is beyond the scope of the present study, the observations arise curiosity, and needs further investigation. When the associations between the presence of tet genes to AMR phenotypes were calculated, there was statistically significant positive associations for the presence of tet genes with resistance phenotypes of the first generation tetracycline (TE and OTC), suggesting that presence of tetB / tetH can be significant predictor of phenotypic resistance to first generation tetracycline, which is the most commonly used antibiotic against Vibrio spp. infections in aquaculture practices of Asian countries (Olatoye and Basiru, 2013). Simultaneously, presence of these tet genes did not cause any resistance to doxycycline, supporting the hypothesis that most tetracycline efflux pumps confer resistance to first generation tetracycline, but are less effective against second generation like, doxycycline (Nguyen et al., 2014). Further, a positive association was observed tetH gene with resistance phenotype to first and second generation cephalosporins (CEP, CX) and gentamicin. tetH gene has already been linked to the resistance genes conferring resistance to sulfamethoxazole and streptomycin (Roberts, 2005; Jia et al., 2016), while our observation on the association between tetH to the first and second generation cephalosporin (CEP, CX) and gentamicin has not been previously reported. However, it was significant to note that statistical associations seen between first generation tetracycline and first generation cephalosporin was matched by an association between tetH gene to this resistant phenotype. In short, analysis of associations of AMR phenotypes/genes aligns with the opinion that there might be a linkage between many of AMR genes on mobile genetic elements and, thus, co-transmission of different AMR phenomenon is possible between bacteria (Boerlin et al., 2005). This also alarms that the use of a particular antimicrobial can select for resistance not only to its own, but also potentially to a variety of other antimicrobials as originally suggested by Gow et al. (2008).

The paper unravels certain interesting observations on the virulence and antibiotic resistance characteristics of three Vibrio spp. that are significant in both aquaculture and public health perspectives, isolated from natural disease outbreaks of marine/estuarine fishes of India during 2017-2019. As the number of natural disease outbreaks caused by these targeted pathogens during the study period are limited, results of the present investigation demands future research targeting higher numbers from a wider area/study period. Nevertheless, as these isolates were representatives of unique and unrelated natural disease outbreaks from a totally unrelated span of areas, from many of the fish species cultured in marine/estuarine environments, the results form a glimpse on the characteristics of these pathogens circulating among various aquaculture systems. Thus, the findings can serve as the baseline data for epizootic tracking and to devise efficient control measures against these three Vibrio spp., in marine/estuarine aquaculture systems in future studies. Nevertheless, future research targeting comparative studies including human clinical isolates and environmental isolates are warranted to elucidate the risk factors and to reveal the mechanisms and frequency of spill over between different compartments. Further, absence of many AR genes in the presence of the corresponding resistance phenotype warrant future genetic studies targeting diverse genes on these isolates. Meanwhile, future research targeting alternative nonantibiotic based therapeutic interventions such as exploitation of lytic bacteriophages and quorum quenchers are also required against bacterial infections in aquaculture premises.

\section{Conclusion}

The paper forms the first report unravelling the virulence and antibiotic resistance characteristics of $V$. parahaemolyticus, $V$. harveyi and $V$. vulnificus isolates from natural disease outbreaks of marine/estuarine fishes of India for the first time. Results showed that V. parahaemolyticus strains of diseased fish were not associated with human clinical strains. However, the data warns on the public health risk potential of V. vulnificus associated with diseased fishes. Analysis taking into consideration of percentage prevalence of susceptible isolates and variation coefficient of inhibition zone diameters, recommended the use of 4 antibiotics viz., imipenem, chloramphenicol, doxycycline and cotrimoxazole for the treatment of all the targeted Vibrio spp. infections. Additionally, all the 17 antibiotics were categorized based on their efficacy against each pathogenic species. MAR indexing and MDR\% has revealed that $>50 \%$ of the isolates came from low antibiotic usage area, suggesting that AMR in pathogens of marine/estuarine fishes of India is in its infancy. However, the need for continuous monitoring of AMR patterns should not be ignored. Analysis of AR genes showed that presence of tetB / tetH can be significant predictor of phenotypic resistance to the first generation tetracycline, the most commonly used antibiotic against Vibrio spp. in aquaculture practices. Further, the study forms the first description of tetH gene sequence in $V$. parahaemolyticus. The data on associations between AMR features, alarms that the use of a particular antimicrobial can select for cross-resistance to other antimicrobials. Altogether, the paper forms critical insights on the virulence and AMR features of the three Vibrio spp. that can pose severe infections in both aquaculture and public health. The generated results serve as the baseline data for epizootic tracking and to devise efficient control measures against these three Vibrio spp. in marine/estuarine aquaculture systems.

\section{Author contributions}

STG conceptualized the presented idea, supervised the findings, analysed the results and wrote the manuscript. MS performed the 
experiments and combined the observations. AVN and APV provided technical support to carry out the experiments. RKJ helped in the sample processing and drafting the manuscript. SA provided feedback in final drafting of the manuscript. NKS supervised the project and acquired financial support for the project leading to this publication.

\section{Declaration of Competing Interest}

None.

\section{Acknowledgements}

The authors are grateful to the Head, Marine Biotechnology Division and the Director, ICAR-Central Marine Fisheries Research Institute, Kochi for providing necessary facilities to carry out the present investigation. A.P.V acknowledges CSIR-UGC for the research fellowship. This work was supported by ICAR-CMFRI funded project "Health Management in selected finfish and shellfish and bioprospecting from marine resources" (MBT/HLT/23) and research contingency amount for BSc-MSc Integrated Biotechnology Course students by Kerala Agricultural University, Thrissur to M.S.

\section{Appendix A. Supplementary data}

Supplementary data to this article can be found online at https://doi. org/10.1016/j.aquaculture.2021.736608.

\section{References}

Aguirre-Guzman, G., Mejia Ruiz, H., Ascencio, F., 2004. A review of extracellular virulence product of Vibrio species important in diseases of cultivated shrimp. Aquac. Res. 35, 1395-1404.

Al-Othrubi, S.M.Y., Kqueen, C.Y., Mirhosseini, H., Hadi, Y.A., Radu, S., 2014. Antibiotic resistance of Vibrio parahaemolyticus isolated from cockles and shrimp sea food marketed in Selangor, Malaysia. Clin. Microbiol. 3, 148.

Arora, N.K., Verma, M., 2017. Modified microplate method for rapid and efficient estimation of siderophore produced by bacteria. Biotech. 7 (6), 381.

Austin, B., 2010. Vibrios as causal agents of zoonoses. Vet. Microbiol. 140, 310-317.

Austin, D.J., Anderson, R.M., 1999. Studies of antibiotic resistance within the patient, hospitals and the community using simple mathematical models. Philosophical Transactions of the Royal Society of London. Series B: Biol. Sci. 354 (1384), 721-738.

Austin, B., Zhang, X.H., 2006. Vibrio harveyi: a significant pathogen of marine vertebrates and invertebrates. Lett. Appl. Microbiol. 43, 119-124.

Babetsa, M., Vassilios, S., Vougidou, C., Zdragas, A., Sivropoulou, A., Psaroulaki, A., Ekateriniadou, L.V., 2012. Tetracycline resistance genes in Pasteurella multocida isolates from bovine, ovine, caprine and swine pneumonic lungs originated from different Greek prefectures. Afr. J. Microbiol. Res. 6 (17), 3917-3923.

Baron, S., Ceccarelli, D., Dalsgaard, I., Granier, S.A., Haenen, O., Jansson, E., Madsen, L., Jouy, E., Kempf, I., Larvor, E., Morin, T., 2020. Influence of incubation time on antimicrobial susceptibility testing of pathogenic Vibrio anguillarum and Vibrio vulnificus isolated from fish. Aquaculture 735258.

Bauer, A.W.W.M., Kirby, W.M.M., Sherris, J.C.T., 1966. Antibiotic susceptibility testing by a standardized single disk method. Am. J. Clin. Pathol. 45 (4), 493.

Beceiro, A., Tomás, M., Bou, G., 2013. Antimicrobial resistance and virulence: a successful or deleterious association in the bacterial world? Clin. Microbiol. Rev. 26 (2), 185-230.

Bergey, D., Whitman, W., Goodfellow, M., Kaampfer, P., Busse, H., 2012. Bergey's Manual of Systematic Bacteriology. Springer, New York.

Boerlin, P., Travis, R., Gyles, C.L., Reid-Smith, R., Lim, N.J.H., Nicholson, V., McEwen, S. A., Friendship, R., Archambault, M., 2005. Antimicrobial resistance and virulence genes of Escherichia coli isolates from swine in Ontario. Appl. Environ. Microbiol. 71 (11), 6753-6761.

Cano-Gómez, A., 2012. Molecular identification of Vibrio harveyi-related bacteria and Vibrio owensii sp. nov., pathogenic to larvae of the ornate spiny lobster Panulirus ornatus (Doctoral dissertation, James Cook University).

Cesur, S., Demiröz, A.P., 2013. Antibiotics and the mechanisms of resistance to antibiotics. Med. J. Islamic World Acad. Sci. 109 (1007), 1-5.

Chan, W.L., Chan, C.H.S., Chan, T.Y.K., 1999. Vibrio vulnificus septicaemia and necrotizing fasciitis after a prick from the dorsal fin of a tilapia. Trans. R. Soc. Trop. Med. Hyg. 93 (2), 174.

Chao, G., Jiao, X., Zhou, X., Yang, Z., Huang, J., Pan, Z., Zhou, L., Qian, X., 2009. Serodiversity, pandemic O3:K6 clone, molecular typing, and antibiotic susceptibility of foodborne and clinical Vibrio parahaemolyticus isolates in Jiangsu, China. Foodborne Pathog. Dis. 6, 1021-1028.
Chatterjee, S., Haldar, S., 2012. Vibrio related diseases in aquaculture and development of rapid and accurate identification methods. J. Marine Sci. Res. Develop. S 1 (1), $1-7$.

CLSI (Clinical and Laboratory Standards Institute), 2006. Methods for Antimicrobial Disk Susceptibility Testing of Bacteria Isolated from Aquatic Animals; Approved Guideline. VET03-A. Clinical and Laboratory Standards Institute, Wayne, PA.

CLSI (Clinical and Laboratory Standards Institute), 2017. Performance Standards for Antimicrobial Susceptibility Testing. M100-S27. Clinical and Laboratory Standards Institute, Wayne, PA.

Crewson, P., 2006. Applied Statistics Handbook. Acastat software version 1.2. http s://www.acastat.com.

Dang, H., Zhang, X., Song, L., Chang, Y., Yang, G., 2006. Molecular characterizations of oxytetracycline resistant bacteria and their resistance genes from mariculture waters of China. Mar. Pollut. Bull. 52 (11), 1494-1503.

de Menezes, F.G.R., Neves, S.S., dos Santos Rocha, R., Sousa, O.V., Torres, M.T.R. Maggioni, R., Hofer, E., dos Fernandes Vieira, R.H.S., 2020. Pathogenic potential of Vibrio parahaemolyticus isolated from tropical estuarine environments in Ceará, Brazil. J. Trop. Pathol. 49 (2), 94-104.

Deng, Y., Xu, L., Chen, H., Liu, S., Guo, Z., Cheng, C., Ma, H., Feng, J., 2020. Prevalence, virulence genes, and antimicrobial resistance of Vibrio species isolated from diseased marine fish in South China. Sci. Rep. 10 (1), 1-8.

Di Pinto, A., Ciccarese, G., Tantillo, G., Catalano, D., Forte, V.T., 2005. A collagenasetargeted multiplex PCR assay for identification of Vibrio alginolyticus, Vibrio cholerae, and Vibrio parahaemolyticus. J. Food Prot. 68 (1), 150-153.

Drais, A.A., Alwan, M.G., Bloh, A.H., Ahmad, A., Sahrani, F.K., Usup, G., 2018. Detection of virulence genes, antibiotic resistance genes, plasmid profile and molecular typing among Vibrio vulnificus isolated from Malaysian seawater and sediment. Int. J. Adv. Sci. Tech. Res. 8 (4), 99-114.

Elmahdi, S., DaSilva, L.V., Parveen, S., 2016. Antibiotic resistance of Vibrio parahaemolyticus and Vibrio vulnificus in various countries: a review. Food Microbiol. 57, 128-134.

Furushita, M., Shiba, T., Maeda, T., Yahata, M., Kaneoka, A., Takahashi, Y., Torii, K., Hasegawa, T., Ohta, M., 2003. Similarity of tetracycline resistance genes isolated from fish farm bacteria to those from clinical isolates. Appl. Environ. Microbiol. 69 (9), 5336-5342.

Gomez-Gil, B., Soto-Rodríguez, S., Lozano, R., Betancourt-Lozano, M., 2014. Draft genome sequence of Vibrio parahaemolyticus strain M0605, which causes severe mortalities of shrimps in Mexico. Genome Announc. 2 (2) e00055-14.

Gow, S.P., Waldner, C.L., Harel, J., Boerlin, P., 2008. Associations between antimicrobial resistance genes in fecal generic Escherichia coli isolates from cow-calf herds in western Canada. Appl. Environ. Microbiol. 74 (12), 3658-3666.

Gufe, C., Canaan Hodobo, T., Mbonjani, B., Majonga, O., Marumure, J., Musari, S., Jongi, G., Makaya, P.V., Machakwa, J., 2019. Antimicrobial profiling of bacteria isolated from fish sold at informal market in Mufakose, Zimbabwe. Int. J. Microbiol. https://doi.org/10.1155/2019/8759636.

Hatha, M., Vivekanandhan, A.A., Joice, G.J., 2005. Antibiotic resistance pattern of motile aeromonads from farm raised fresh water fish. Int. J. Food Microbiol. 98 (2), $131-134$.

Honda, T., Iida, T., 1993. The pathogenicity of Vibrio parahaemolyticus and the role of the thermostable direct haemolysin and related haemolysins. Rev. Med. Microbiol. 4 (2), 106-113.

Hwang, T.J., Hooper, D.C., 2014. Association between fluoroquinolone resistance and resistance to other antimicrobial agents among Escherichia coli urinary isolates in the outpatient setting: a national cross-sectional study. J. Antimicrob. Chemother. 69 (6), 1720.

Jia, B., Raphenya, A.R., Alcock, B., Waglechner, N., Guo, P., Tsang, K.K., Lago, B.A., Dave, B.M., Pereira, S., Sharma, A.N., Doshi, S., 2016. CARD 2017: expansion and model-centric curation of the comprehensive antibiotic resistance database. Nucleic Acids Res. D1, D566-D573.

Kathleen, M.T., Samuel, L., Felecia, C., Reagan, E.T., Kasing, A., Lesley, M., Toh, S.T., 2016. Antibiotic resistance of diverse bacteria from aquaculture in Borneo. Int. J. Med. Microbiol. 2016, 2164761. https://doi.org/10.1155/2016/2164761.

Kautsky, N., Rönnbäck, P., Tedengren, M., Troell, M., 2000. Ecosystem perspectives on management of disease in shrimp pond farming. Aquaculture 191 (1-3), 145-161.

Kaysner, C.A., DePaola, A., 2004. Vibrio. Bacteriological Analytical Manual Online. U.S. Food and Drug Administration, Washington, DC.

Kehrenberg, C., Schulze-Tanzil, G., Martel, J.L., Chaslus-Dancla, E., Schwarz, S., 2001. Antimicrobial resistance in Pasteurella and Mannheimia: epidemiology and genetic basis. Vet. Res. 32 (3-4), 323-339.

Khouadja, S., Lamari, F., Bakhrouf, A., 2013. Characterization of Vibrio parahaemolyticus isolated from farmed sea bass (Dicentrarchus labrax) during disease outbreaks. Int. Aquat. Res. 5 (1), 13.

Kitiyodom, S., Khemtong, S., Wongtavatchai, J., Chuanchuen, R., 2010. Characterization of antibiotic resistance in Vibrio spp. isolated from farmed marine shrimps (Penaeus monodon). FEMS Microbiol. Ecol. 72 (2), 219-227.

Krumperman, P.H., 1983. Multiple antibiotic resistance indexing of Escherichia coli to identify high-risk sources of faecal contamination of foods. Appl. Environ. Microbiol. 46 (1), 165-170.

Kumar, S., Stecher, G., Tamura, K., 2016. MEGA7: molecular evolutionary genetics analysis version 7.0 for bigger datasets. Mol. Biol. Evol. 33 (7), 1870-1874.

Lakhssassi, N., Elhajoui, N., Lodter, J.P., Pineill, J.L., Sixou, M., 2005. Antimicrobial susceptibility variation of 50 anaerobic periopathogens in aggressive periodontitis: an interindividual variability study. Oral Microbiol. Immunol. 20 (4), 244-252.

Lim, M.H., Kasing, A., 2013. Antimicrobial susceptibilities of Vibrio parahaemolyticus isolates from tiger shrimps (Penaeus monodon) aquaculture in Kuching, Sarawak. Res. J. Microbiol. 8 (1), 55-62. 
Lin, Z., Kumagai, K., Baba, K., Mekalanos, J.J., Nishibuchi, M., 1993. Vibrio parahaemolyticus has a homolog of the Vibrio cholera toxR operon that mediates environmentally induced regulation of the thermostable direct hemolysin gene. J. Bacteriol. 175, 3844-3855.

Litwin, C.M., Rayback, T.W., Skinner, J., 1996. Role of catechol siderophore synthesis in Vibrio vulnificus virulence. Infect. Immun. 64, 2834-2838.

Magiorakos, A.P., Srinivasan, A., Carey, R.B., Carmeli, Y., Falagas, M.E., Giske, C.G., Harbarth, S., Hindler, J.F., Kahlmeter, G., Olsson-Liljequist, B., Paterson, D.L., 2012. Multidrug-resistant, extensively drug-resistant and pandrug-resistant bacteria: an international expert proposal for interim standard definitions for acquired resistance. Clin. Microbiol. Infect. 18 (3), 268-281.

Mala, W., Alam, M., Angkititrakul, S., Wongwajana, S., Lulitanond, V., Huttayananont, S., Kaewkes, W., Faksri, K., Chomvarin, C., 2016. Serogroup, virulence, and molecular traits of Vibrio parahaemolyticus isolated from clinical and cockle sources in North-Eastern Thailand. Infect. Genet. Evol. 39, 212-218.

Marotta, F., Garofolo, G., Di Marcantonio, L., Serafino, Di, Neri, D., Romantini, R., Sacchini, L., Alessiani, A., Di Donato, G., Nuvoloni, R., Janowicz, A., 2019. Antimicrobial resistance genotypes and phenotypes of Campylobacter jejuni isolated in Italy from humans, birds from wild and urban habitats, and poultry. PLoS One 14 (10), e0223804.

Mellado, J.R., Freedman, A.L., Salkin, L.M., Stein, M.D., Schneider, D.B., Cutler, R.H., 2001. The clinical relevance of microbiologic testing: a comparative analysis of microbiologic samples secured from the same sites and cultured in two independent laboratories. Int J Periodontics Restorative Dent 23 (2), 121-127.

Miller, R.A., Harbottle, H., 2018. Antimicrobial drug resistance in fish pathogens. Antimicrobial resistance in bacteria from livestock and companion animals, pp. 501-520.

Mohamad, N., Amal, M.N.A., Saad, M.Z. Md Yasin, I.S., Zulkiply, N.M., Mustafa, M., Nasruddin, N.S., 2019. Virulence-associated genes and antibiotic resistance pattern of Vibrio spp. isolated from cultured marine fishes in Malaysia. BMC Vet. Res. 15, 176.

Moreno, M.L., Landgraf, M., 1998. Virulence factors and pathogenicity of Vibrio vulnificus strains isolated from seafood. J. Appl. Microbiol. 84, 747-751.

Narayanan, S.V., Joseph, T.C., Peeralil, S., Koombankallil, R., Vaiyapuri, M., Mothadaka, M.P., Lalitha, K.V., 2020. Tropical shrimp aquaculture farms harbour pathogenic Vibrio parahaemolyticus with high genetic diversity and carbapenam resistance. Mar. Pollut. Bull. 160, 111551.

NARMS (National Antimicrobial Resistance Monitoring System), 2019. National Antimicrobial Resistance Monitoring System for Enteric Bacteria. Centers for Disease Control and Prevention, Atlanta, GA. https://www.cdc.gov/narms/antibiotics-teste d.html.

Nasaj, M., Saeidi, Z., Asghari, B., Roshanaei, G., Arabestani, M.R., 2020. Identification of hemolysin encoding genes and their association with antimicrobial resistance pattern among clinical isolates of coagulase-negative staphylococci. BMC Res. Notes 13 (1), 68.

Naylor, R.L., Goldburg, R.J., Primavera, J.H., Kautsky, N., Beveridge, M.C., Clay, J., Folke, C., Lubchenco, J., Moone, H., Troell, M., 2000. Effect of aquaculture on world fish supplies. Nature 405 (6790), 1017-1024.

Neela, F.A., Nonaka, L., Rahman, M.H., Suzuki, S., 2009. Transfer of the chromosomally encoded tetracycline resistance gene tet $(M)$ from marine bacteria to Escherichia coli and Enterococcus faecalis. World J. Microbiol. Biotechnol. 25 (6), 1095-1101.

Nguyen, H.N.K., Van, T.T.H., Nguyen, H.T., Smooker, P.M., Shimeta, J., Coloe, P.J., 2014. Molecular characterization of antibiotic resistance in Pseudomonas and Aeromonas isolates from catfish of the Mekong Delta, Vietnam. Vet. Microbiol. 171 (3-4), 397-405.

Noguerola, I., Blanch, A.R., 2008. Identification of Vibrio spp. with a set of dichotomous keys. J. Appl. Microbiol. 105 (1), 175-185.

Olatoye, I.O., Basiru, A., 2013. Antibiotic usage and oxytetracycline residue in African catfish (Clarias gariepinus) in Ibadan, Nigeria. World J. Fish Mar. Sci. 5, 302-309.

Olsen, R.L., Hasan, M.R., 2012. A limited supply of fishmeal: impact on future increases in global aquaculture production. Trends Food Sci. Technol. 27 (2), 120-128.

Osundiya, O.O., Oladele, R.O., Oduyebo, O.O., 2013. Multiple antibiotic resistance (MAR) indices of Pseudomonas and Klebsiella species isolates in Lagos University Teaching Hospital. Afr. J. Clin. Exp. Microbiol. 14 (3), 164-168.

Ottaviani, D., Bacchiocchi, I., Masini, L., Leoni, F., Carraturo, A., Giammarioli, M., Sbaraglia, G., 2001. Antimicrobial susceptibility of potentially pathogenic halophilic vibrios isolated from seafood. Int. J. Antimicrob. Agents 18 (2), 135-140.

Ottaviani, D., Santarelli, S., Bacchiocchi, S., Masini, L., Ghittino, C., Bacchiocchi, I., 2005. Presence of pathogenic Vibrio parahaemolyticus strains in mussels from the Adriatic Sea, Italy. Food Microbiol. 22 (6), 585-590.

Parthasarathy, S., Das, S.C., Kumar, A., 2016. Occurrence of pathogenic Vibrio parahaemolyticus in crustacean shellfishes in coastal parts of Eastern India. Vet. World 9 (3), 330.

Pedersen, K., Skall, H.F., Lassen-Nielsen, A.M., Nielsen, T.F., Henriksen, N.H., Olesen, N. J., 2008. Surveillance of health status on eight marine rainbow trout, Oncorhynchus mykiss (Walbaum), farms in Denmark in 2006. J. Fish Dis. 31, 659-667.

Preena, P.G., Dharmaratnam, A., Raj, N.S., Kumar, T.V.A., Raja, S.A., Nair, R., Swaminathan, T.R., 2020. Diversity of antimicrobial resistant pathogens from a freshwater ornamental fish farm. Lett. Appl. Microbiol. 71 (1), 108-116.
Raissy, M., Moumeni, M., Ansari, M., Rahimi, E., 2012. Antibiotic resistance pattern of some Vibrio strains isolated from seafood. Iran. J. Fish. Sci. 11 (3), 618-626.

Roberts, M.C., 1996. Tetracycline resistance determinants: mechanisms of action, regulation of expression, genetic mobility, and distribution. FEMS Microbiol. Rev. 19 (1), 1-24.

Roberts, M.C., 2005. Update on acquired tetracycline resistance genes. FEMS Microbiol. Lett. 245 (2), 195-203.

Roig, F.J., Sanjuán, E., Llorens, A., Amaro, C., 2010. pilF polymorphism-based PCR to distinguish Vibrio vulnificus strains potentially dangerous to public health. Appl. Environ. Microbiol. 76 (5), 1328-1333.

Rosengren, L.B., Waldner, C.L., Reid-Smith, R.J., 2009a. Associations between antimicrobial resistance phenotypes, antimicrobial resistance genes, and virulence genes of faecal Escherichia coli isolates from healthy grow-finish pigs. Appl. Environ. Microbiol. 75 (5), 1373-1380.

Rosengren, L.B., Waldner, C.L., Reid-Smith, R.J., Valdivieso-Garcia, A., 2009b. Associations between antimicrobial exposure and resistance in faecal Campylobacter spp. from grow-finish pigs on-farm in Alberta and Saskatchewan, Canada. J. Food Prot. 72 (3), 482-489.

Ruwandeepika, H.A.D., Defoirdt, T., Bhowmick, P.P., Shekar, M., Bossier, P., Karunasagar, I., 2010. Presence of typical and atypical virulence genes in vibrio isolates belonging to the Harveyi clade. J. Appl. Microbiol. 109 (3), 888-899.

Safain, K.S., Bhuyan, G.S., Tasnim, S., Hasib, S., Sultana, R., Islam, S., Al Mahmud-UnNabi, M., Sarker, S.K., Noor, F.A., Rahat, A., Bhuiyan, M.A.M., 2020. Situation of antibiotic resistance in Bangladesh and its association with resistance genes for horizontal transfer. bioRxiv. https://doi.org/10.1101/2020.04.06.027391.

Sapkota, A., Sapkota, A.R., Kucharski, M., Burke, J., McKenzie, S., Walker, P., Lawrence, R., 2008. Aquaculture practices and potential human health risks: current knowledge and future priorities. Environ. Int. 34 (8), 1215-1226.

Sawabe, T., Ogura, Y., Matsumura, Y., Gao, F., Amin, A.K.M., Mino, S., Nakagawa, S., Sawabe, T., Kumar, R., Fukui, Y., Satomi, M., 2013. Updating the Vibrio clades defined by multilocus sequence phylogeny: proposal of eight new clades, and the description of Vibrio tritonius sp. nov. Front. Microbiol. 4, 414.

Schroeder, M., Brooks, B.D., Brooks, A.E., 2017. The complex relationship between virulence and antibiotic resistance. Genes 8 (1), 39.

Selven, S., Philip, R., 2012. Salinity induced haematological inflection in Indian white shrimp, Fenneropenaeus indicus (H. Milne-Edwards, 1837). Asian Fish. Sci. 25 (2), 170-179.

Senoh, M., Miyoshi, S.I., Okamoto, K., Fouz, B., Amaro, C., Shinoda, S., 2005. The cytotoxin-hemolysin genes of human and eel pathogenic Vibrio vulnificus strains: comparison of nucleotide sequences and application to the genetic grouping. Microbiol. Immunol. 49 (6), 513-519.

Soto-Rodriguez, S.A., Roque, A., Lizarraga-Partida, M.L., Guerra-Flores, A.L., GomezGil, B., 2003. Virulence of luminous vibrios to Artemia franciscana nauplii. Dis. Aquat. Org. 53, 231-240.

Tsukamoto, N., Ohkoshi, Y., Okubo, T., Sato, T., Kuwahara Fujii, N., Tamura, Y., Yokota, S.I., 2013. High prevalence of cross-resistance to aminoglycosides in fluoroquinolone-resistant Escherichia coli clinical isolates. Chemotherapy 59 (5), 379-384.

Van, C.N., Zhang, L., Thi Thanh, T.V., Son, H.P.H., Ngoc, T.T., Huang, Q., Zhou, R., 2020. Association between the phenotypes and genotypes of antimicrobial resistance in Haemophilus parasuis isolates from swine in Quang Binh and Thua Thien Hue Provinces, Vietnam. Engineering 6 (1), 40-48.

Vinh, D.C., Mubareka, S., Fatoye, B., Plourde, P., Orr, P., 2006. Vibrio vulnificus septicemia after handling Tilapia species fish: a Canadian case report and review. Can. J. Infect. Dis. Med. Microbiol. 17 (2), 129-132.

Watts, J.E., Schreier, H.J., Lanska, L., Hale, M.S., 2017. The rising tide of antimicrobial resistance in aquaculture: sources, sinks and solutions. Mar. Drugs 15 (6), 158.

Weisburg, W.G., Barns, S.M., Pelletier, D.A., Lane, D.J., 1991. 16S ribosomal DNA amplification for phylogenetic study. J. Bacteriol. 173 (2), 697-703.

Wilson, K., 1987. Preparation of genomic DNA from bacteria. In: Ausubel, F.M., Brent, R., Kingston, R.E., Moore, D.D., Seidman, J.G., Smith, J.A. (Eds.), Current Protocols in Molecular Biology. Wiley, New York.

Xu, Y., Wang, C., Zhang, G., Tian, J., Liu, Y., Shen, X., Feng, J., 2017. ISCR2 is associated with the dissemination of multiple resistance genes among Vibrio spp. and Pseudoalteromonas spp. isolated from farmed fish. Arch Microbiol 199 (6), 891-896.

Yang, Y., Xie, J., Li, H., Tan, S., Chen, Y., Yu, H., 2017. Prevalence, antibiotic susceptibility and diversity of Vibrio parahaemolyticus isolates in seafood from South China. Front. Microbiol. 82566.

Zhang, X.H., Austin, B., 2000. Pathogenicity of Vibrio harveyi to salmonids. J. Fish Dis. 23 (2), 93-102.

Zhang, X.H., He, X., Austin, B., 2020. Vibrio harveyi: a serious pathogen of fish and invertebrates in mariculture. Mar. Life Sci. Technol. 2, 231-245.

Zhao, F., Zhou, D.Q., Cao, H.H., Ma, L.P., Jiang, Y.H., 2011. Distribution, serological and molecular characterization of Vibrio parahaemolyticus from shellfish in the eastern coast of China. Food Control 22 (7), 1095-1100.

Zhu, Z.M., Dong, C.F., Weng, S.P., He, J.G., 2017. The high prevalence of pathogenic Vibrio harveyi with multiple antibiotic resistance in scale drop and muscle necrosis disease of the hybrid grouper, Epinephelus fuscoguttatus $(\%) \times \mathrm{E}$. lanceolatus ( $\left(\mathrm{d}^{\mathrm{r}}\right)$, in China. J Fish Dis 19 (4), 191-198. 